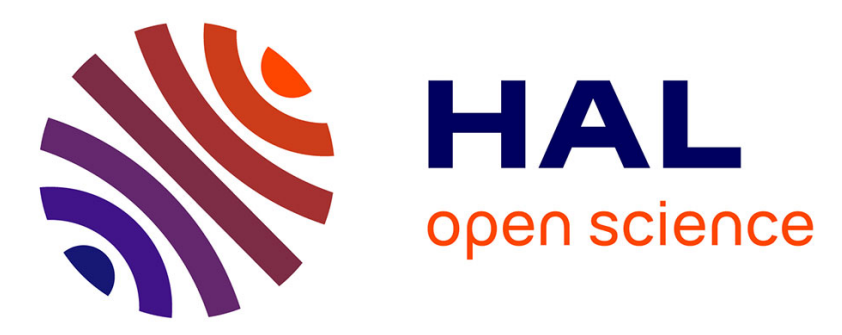

\title{
Biochemical and structural characterization of the novel sialic acid-binding site of Escherichia coli heat-labile enterotoxin LT-IIb
}

Dani Zalem, Joao Ribeiro, Annabelle Varrot, Michael Lebens, Anne Imberty, Susann Teneberg

\section{To cite this version:}

Dani Zalem, Joao Ribeiro, Annabelle Varrot, Michael Lebens, Anne Imberty, et al.. Biochemical and structural characterization of the novel sialic acid-binding site of Escherichia coli heat-labile enterotoxin LT-IIb. Biochemical Journal, 2016, 473 (21), pp.3923-3936. 10.1042/BCJ20160575 . hal-02381852

\section{HAL Id: hal-02381852 \\ https://hal.science/hal-02381852}

Submitted on 26 Nov 2019

HAL is a multi-disciplinary open access archive for the deposit and dissemination of scientific research documents, whether they are published or not. The documents may come from teaching and research institutions in France or abroad, or from public or private research centers.
L'archive ouverte pluridisciplinaire HAL, est destinée au dépôt et à la diffusion de documents scientifiques de niveau recherche, publiés ou non, émanant des établissements d'enseignement et de recherche français ou étrangers, des laboratoires publics ou privés. 


\section{Biochemical and structural characterization of the novel sialic acid-binding site of Escherichia coli heat-labile enterotoxin LT-IIb}

Dani Zalem ${ }^{1}$, João P. Ribeiro ${ }^{2}$, Annabelle Varrot ${ }^{2}$, Michael Lebens ${ }^{3}$, Anne Imberty ${ }^{2}$, and Susann Teneberg, ${ }^{1, *}$

${ }^{1}$ Institute of Biomedicine, Department of Medical Biochemistry and Cell Biology, University of Gothenburg, Göteborg, Sweden

${ }^{2}$ Centre de Recherches sur les Macromolécules Végétales (UPR5301, CNRS and University Grenoble Alpes), BP53, F-38041 Grenoble Cedex 09, France

${ }^{3}$ Institute of Biomedicine, Department of Medical Microbiology and Immunology, University of Gothenburg, Göteborg, Sweden

*Correspondence: Susann.Teneberg@medkem.gu.se 


\section{ABSTRACT}

The structurally related $\mathrm{AB}_{5}$-type heat-labile enterotoxins of Escherichia coli and Vibrio cholerae are classified into two major types. The type I group includes cholera toxin and $E$. coli LT-I, while the type II subfamily comprises LT-IIa, LT-IIb and LT-IIc. The carbohydrate binding specificities of LT-IIa, LT-IIb and LT-IIc are distinctive from those of cholera toxin and E. coli LT-I. While CT and LT-I bind primarily to the GM1 ganglioside, LT-IIa binds to gangliosides GD1a, GD1b, and GM1, LT-IIb binds only to the GD1a ganglioside, and LT-IIc binds to GM1, GM2, GM3 and GD1a. Previous studies of the binding properties of type II Bsubunits have been focused on ganglio core chain gangliosides. To further define the carbohydrate binding specificity of LT-IIb B-subunits, we have herein investigated its binding to a collection of gangliosides and non-acid glycosphingolipids with different core chains. A high affinity binding of LT-IIb B-subunits to gangliosides with neolacto core chain, as e.g. NeuGco3- and NeuAco3-neolactohexaosylceramide, and NeuGco3- and NeuAc $\alpha 3-$ neolactooctaosylceramide was detected. An LT-IIb binding ganglioside was isolated from human small intestine and characterized as NeuAc $\alpha 3$-neolactohexaosylceramide. The crystal structure of B-subunit of LT-IIb with the pentasaccharide moiety of NeuAca3neolactotetraosylceramide (NeuAc-nLT: NeuAc $\alpha 3$ Gal $\beta 4$ GlcNAc $\beta 3$ Gal $\beta 4 G l c)$ was determined providing the first information for sialic binding site in this sub-family, with clear differences with the one from CT and LT-I. 


\section{Summary statement (25 words)}

LT-IIb, a toxin from diarrhea-causing Escherichia coli binds to sialylated glycoconjugates on target tissues, and present only partial similarity with the cholera toxin.

\section{Short title}

Novel carbohydrate-binding site of E. coli heat-labile enterotoxin LT-IIb (74 characters)

\section{Keywords}

Toxin B-subunit, carbohydrate-binding site, sialic acid binding.

\section{Abbreviations}

CT, cholera toxin; ETEC, enterotoxigenic Escherichia coli; LC-ESI/MS; liquid chromatography/electrospray ionization mass spectrometry; LTs, E. coli heat-labile enterotoxins; LT-I, E. coli heat-labile enterotoxin type I; LT-IIa, E. coli heat-labile enterotoxin type IIa; LT-IIb, E. coli heat-labile enterotoxin type IIb; LT-IIc, E. coli heat-labile enterotoxin type IIc; NeuAc-nLT: NeuAc $\alpha 3$ Galß4GlcNAcß3Galß4Glc; RT, room temperature. 


\section{INTRODUCTION}

Enterotoxigenic Escherichia coli (ETEC) is the cause of diarrheal diseases leading to several hundred million cases of diarrhea and several ten of thousand deaths annually [1]. The diarrhea is mainly due to the action of enterotoxins released from the bacteria. ETEC produces both heat-stable and heat-labile (LTs) enterotoxins. The LTs belong to $\mathrm{AB}_{5}$ toxins, a family of oligomeric proteins consisting of an A-subunit with catalytic activity and a pentameric B-subunit responsible for the binding to host glycoconjugates $[2,3]$. ETEC enterotoxins together with cholera toxin $(\mathrm{CT})$ constitute one of the four subgroups of $\mathrm{AB}_{5}$ toxins [3].

The family of ETEC enterotoxins is divided into type I and type II, where the type I Bsubunits are most related to the CT B-subunits. There are three members of the ETEC type II heat-labile enterotoxins: LT-IIa, LT-IIb, and LT-IIc. The amino acid sequences of these Asubunits have only approximately 50-60\% identity with the A-subunits of CT/LT type I, and there is no amino acid homology between the type II B-subunits and CT/LT type I B-subunits [4].

LTs and CT receptors are mainly gangliosides, a subclass of glycosphingolipids containing one or several sialic acid residues. Glycosphingolipids are classified on the basis of their carbohydrate core structures. In humans the lacto/type 1 (Galß3GlcNAc), neolacto/type 2 (Galß4GlcNAc), and globo/type 4 (Gal $\alpha 4 \mathrm{Gal})$ core chains are the most common in non-acid glycosphingolipids, while gangliosides are mainly based on ganglio (Galß3GalNAc) or neolacto core chains. The primary receptor of B-subunits of CT and LT type I is the GM1 ganglioside [5], although LT type I also binds to glycoconjugates with terminal $\mathrm{N}$ - 
acetyllactosamine $[6,7]$. Binding of type II enterotoxin B-subunits have hitherto only been tested on gangliosides with ganglio core chain, demonstrating that LT-IIa binds to a range of such gangliosides, with highest affinity for the GD1b ganglioside, while LT-IIb interacts preferentially with gangliosides GD1a and GT1b $[8,9]$. The gangliosides recognized by LTIIc are GM1, GM2, GM3 and GD1a [10], with a preference for GM1 with long fatty acyl ceramide chain [9].

While a large amount of CT and LT type 1 structures bound to a variety of glycan receptors are available [11-14], the structural data on LT-IIb is limited $[4,15]$. The overall structure of the LT-IIb holotoxin [4] closely resembles that of CT. Despite of the very limited sequence identity, the B-subunit of LT-IIb adopts a very similar fold as the B-subunits of CT and LT type 1 . The putative ganglioside binding site of LT-IIb was proposed to be located in the same region as the GM1 binding sites of CT and LT type I [4].

In the present work, we further investigated the carbohydrate binding specificity of LT-IIb using our unique collection of gangliosides of various core chain series from different sources [16], and also a number of related non-acid glycosphingolipids. We also determined the first crystal structure of the B-subunit of LT-IIb with a ligand bound, namely with the pentasaccharide moiety of NeuAco3-neolactotetraosylceramide (NeuAc-nLT: NeuAc $\alpha 3$ Gal $\beta 4$ GlcNAc $\beta 3$ Gal $\beta 4 G l c)$ establishing the molecular basis of the specificity and demonstrating the differences with the binding sites of LT-I/CT B-subunits. 


\section{EXPERIMENTAL PROCEDURES}

\section{Production of recombinant LT-IIb B-subunits}

Recombinant LT-IIb B-subunits was produced from a synthetic gene purchased from ATGBiosynthetics GmbH (Freiburg, Germany). This gene contained the entire coding sequence including the signal sequence. The signal peptide was removed by reverse PCR and the resulting plasmid was pML-LTB2b $\Delta \mathrm{s} \lambda \mathrm{cI} 857$. Induction of expression in E. coli strain BL21 gave rise to inclusion bodies containing the LT-IIb gene product.

$25 \mathrm{~mL}$ cultures of $E$. coli BL21 carrying pML-LTB2b $\Delta \mathrm{s} \lambda \mathrm{cI} 857$ were grown in $250 \mathrm{~mL}$ Erlenmeyer flasks in LB broth supplemented with $100 \mu \mathrm{g} / \mathrm{ml}$ ampicillin overnight at $30{ }^{\circ} \mathrm{C}$ with shaking at $180 \mathrm{rpm} .5 \mathrm{~mL}$ aliquots of this culture were used to inoculate $500 \mathrm{~mL}$ fresh LB broth supplemented with $100 \mu \mathrm{g} / \mathrm{ml}$ ampicillin in $2 \mathrm{~L}$ Erlenmeyer flasks. The flasks were incubated for $2 \mathrm{~h}$ at $30{ }^{\circ} \mathrm{C}$ with shaking before induction of LT-IIb B-subunit expression by raising the temperature to $42{ }^{\circ} \mathrm{C}$. The cultures were incubated for a further $3-4 \mathrm{~h}$, and thereafter cells were harvested by centrifugation at 13,000 x g for $20 \mathrm{~min}$, and the pellet was stored at $-20{ }^{\circ} \mathrm{C}$.

Cells were resuspended in Tris-HCl, $50 \mathrm{mM}, \mathrm{pH} \mathrm{8}$, and lysed by treatment with lysozyme $(100 \mathrm{mg} / \mathrm{ml})$ and EDTA $(1 \mathrm{mM})$, at room temperature (RT) for $30 \mathrm{~min} . \mathrm{MgCl}_{2}$ was added to a final concentration of $10 \mathrm{mM}$ followed by a small amount of DNase (Roche). The mixture was incubated for $15 \mathrm{~min}$ at RT and a protease inhibitor cocktail was added at a concentration recommended by the manufacturer (Complete, Roche). Cells were disrupted by sonication on ice for 4-5 min with $2 \mathrm{~s}$ pulses at $2 \mathrm{~s}$ intervals at $60 \%$ amplitude, and the inclusion bodies harvested by centrifugation $(4,000 \mathrm{x} \mathrm{g}, 7 \mathrm{~min})$. The pellet was washed with ice cold phosphate-buffered saline, pH 7.3 (PBS), containing 0.1\% Triton X114 and re-suspended in 
minimal volume of double deionized water. Urea solution $(6.5 \mathrm{M})$ was added and left overnight with stirring at $4{ }^{\circ} \mathrm{C}$. Undissolved debris was then removed by centrifugation at $48,000 \mathrm{x} \mathrm{g}$ for $30 \mathrm{~min}$. The protein was refolded by dialysis overnight at $4{ }^{\circ} \mathrm{C}$ against $2 \mathrm{~L}$ of $50 \mathrm{mM}$ Carbonate buffer ( $\mathrm{pH}$ 9) containing $1 \mathrm{M}$ Urea, followed by further extensive dialysis again the same buffer containing no urea. Insoluble debris was then removed by centrifugation $(48,000 \times \mathrm{g}, 30 \mathrm{~min})$. The supernatant was sterilized by filtration through a 0,22 $\mu \mathrm{m}$ filter. Assembled protein was purified by ion exchange followed size exclusion chromatography.

The protein preparations were analysed on $14 \%$ Tris-Glycine gel (Invitrogen, Carlsbad, CA), according to the instructions of the manufacturer, and stained using Coomassie Brilliant Blue $\mathrm{R}-250$.

\section{Thermal shift assays}

LT-IIb B-subunit samples were diluted to a final protein concentration of $0.1 \mathrm{mg} / \mathrm{mL}$ and mixed with SYPRO Orange (5x) in $25 \mu$. The samples were subjected to thermal denaturation using a Real Time PCR machine with a temperature gradient starting at from 25 and ascending to $100{ }^{\circ} \mathrm{C}$ at a heating rate of $1{ }^{\circ} \mathrm{C} / \mathrm{min}$. Protein unfolding was followed by the increase of the fluorescence values given by the SYPRO Orange probe. Datapoints are from the experimental values and all curves were integrated according to the previously described protocol [17].

\section{Radiolabeling}


Aliquots of $100 \mu \mathrm{g}$ of B-subunits were labeled with ${ }^{125} \mathrm{I}$, using $\mathrm{Na}^{125} \mathrm{I}(100 \mu \mathrm{Ci} / \mathrm{ml}$; Amersham Pharmacia Biotech, Little Chalfont, U.K.), according to the IODO-GEN protocol of the manufacturer (Pierce, Rockford, IL), giving approximately $5 \times 10^{3} \mathrm{cpm} / \mu \mathrm{g}$ protein.

\section{Reference glycosphingolipids}

Total acid and neutral glycosphingolipid fractions were obtained by standard procedures [18]. The individual glycosphingolipids were isolated by repeated chromatography on silicic acid columns of the native glycosphingolipid fractions, or acetylated derivatives thereof. The identity of the purified glycosphingolipids was confirmed by mass spectrometry $[19,20]$ and proton NMR spectroscopy [21].

\section{Thin-layer chromatography}

Precoated silica gel 60 HPTLC plates with either a glass or aluminium support (Merck, Darmstadt, Germany) were used for thin-layer chromatography. The solvent system used for separation of glycosphingolipids was chloroform/methanol/water 60:35:8 (by volume). Glycosphingolipids were detected by the anisaldehyde reagent [22] or the resorcinol reagent $[23]$.

\section{Chromatogram binding assay}

Binding of radiolabeled LT-IIb B-subunits to glycosphingolipids separated on thin-layer chromatograms was performed as described [7]. In short, $20-40 \mu \mathrm{g}$ of mixtures of glycosphingolipids, or $20 \mathrm{ng}-4 \mu \mathrm{g}$ of pure compounds, were separated on aluminium-backed thin-layer plates. Dried chromatograms were dipped for $1 \mathrm{~min}$ in diethylether/n-hexane $(1: 5$, by volume) containing $0.5 \%(\mathrm{w} / \mathrm{v})$ polyisobutylmethacrylate (Aldrich Chem. Comp. Inc., Milwaukee, WI). After drying, the chromatograms were soaked in PBS, containing $2 \%$ 
bovine serum albumin and $0.1 \% \mathrm{NaN}_{3}$ (BSA/PBS), for $2 \mathrm{~h}$ at RT. Thereafter the plates were

incubated with ${ }^{125} \mathrm{I}$-labeled B-subunits diluted in BSA/PBS $\left(1-2 \times 10^{6} \mathrm{cpm} / \mathrm{ml}\right)$ for another $2 \mathrm{~h}$ at RT. After washing six times with PBS, and drying, the thin-layer plates were autoradiographed for 12 h using XAR-5 x-ray films (Eastman Kodak, Rochester, NY).

\section{Isolation of human small intestinal gangliosides recognized by LT-IIb B-subunits}

One total acid glycosphingolipid fraction from human small intestine $(675 \mathrm{mg})$ was separated by repeated silicic acid chromatography, and followed by repeated chromatography on Iatrobeads (Iatrobeads 6RS-8060; Iatron Laboratories, Tokyo) columns, eluted with chloroform/methanol/water 60:35:8 (by volume), and finally chloroform/methanol/water 40:40:12 (by volume). Throughout the separation procedures, aliquots of the fractions obtained were analyzed by thin-layer chromatography, and fractions that were coloured green by anisaldehyde were tested for binding of LT-IIb using the chromatogram binding assay. The fractions were pooled according to the mobility on thin-layer chromatograms and their LT-IIb binding activity.

\section{LC-ESI/MS of the LT-IIb binding acid glycospingolipid fractions from human small} intestine

Aliquots $(20 \mu \mathrm{g})$ of ganglioside fractions A-1 and A-2 from human small intestine were dissolved in methanol:acetonitrile 75:25 (by volume), and separated on a 200x0.150 mm column, packed in-house with $5 \mu \mathrm{m}$ polyamine II particles (YMC Europe GmbH, Dinslaken, Germany). An autosampler, HTC-PAL (CTC Analytics AG, Zwingen, Switzerland) equipped with a cheminert valve $(0.25 \mathrm{~mm}$ bore $)$ and a $2 \mu$ loop was used for sample injection. An Agilent 1100 binary pump (Agilent technologies, Palo Alto, CA) delivered a flow of 250 $\mu \mathrm{l} / \mathrm{min}$, which was split down in an $1 / 16$ " microvolume-T (0.15 $\mathrm{mm}$ bore) (Vici AG 
International, Schenkon, Switzerland) by a $50 \mathrm{~cm}$ x $50 \mu \mathrm{m}$ i.d. fused silica capillary before the injector of the autosampler, allowing approximately $2-3 \mu 1 /$ min through the column. Samples were eluted with an aqueous gradient (A:100\% acetonitrile to B: $10 \mathrm{mM}$ ammonium bicarbonate). The gradient $(0-50 \% \mathrm{~B})$ was eluted for $40 \mathrm{~min}$, followed by a wash step with $100 \% \mathrm{~B}$, and equilibration of the column for $20 \mathrm{~min}$. The samples were analyzed in negative ion mode on a LTQ linear quadrupole ion trap mass spectrometer (Thermo Electron, San José, CA), with an IonMax standard ESI source equipped with a stainless steel needle kept at -3.5 $\mathrm{kV}$. Compressed air was used as nebulizer gas. The heated capillary was kept at $270^{\circ} \mathrm{C}$, and the capillary voltage was $-50 \mathrm{kV}$. Full scan ( $\mathrm{m} / \mathrm{z}$ 500-1800, two microscan, maximum $100 \mathrm{~ms}$, target value of 30,000 ) was performed, followed by data-dependent $\mathrm{MS}^{2}$ scans (two microscans, maximun $100 \mathrm{~ms}$, target value of 10.000) with normalized collision energy of $35 \%$, isolation window of 2.5 units, activation $\mathrm{q}=0.25$ and activation time $30 \mathrm{~ms})$. The threshold for $\mathrm{MS}^{2}$ was set to 500 counts.

Data acquisition and processing were conducted with Xcalibur software (Version 2.0.7). Manual assignment of glycosphingolipid sequences was done with the assistance of the Glycoworkbench tool (Version 2.1), and by comparison of retention times and $\mathrm{MS}^{2}$ spectra of reference glycosphingolipids.

\section{Crystallization and data collection}

A solution of LT-IIb B-subunit $\left(10 \mathrm{mg} \mathrm{ml}^{-1}\right)$ in sodium carbonate $50 \mathrm{mM} \mathrm{pH} 9$ was sent to the High Throughput Crystallization laboratory (HTXlab, EMBL Grenoble, France) to screen for the best crystallization conditions. The protein was tested against the JCSG (Qiagen), Wizard I and II (Rigaku reagents), PACT (Qiagen), PEGS I (Qiagen), and plates 4 and 5 (Hampton) screens. The crystallization conditions that resulted in good quality crystals were reproduced 
in house with the addition of $11 \mathrm{mM}$ NeuAc-nLT (Sialyl-Lacto-N-tetraose from

Elicityl, Crolles, France) to the crystallization buffer. After optimization, high quality crystals were obtained in $0.2 \mathrm{M} \mathrm{KCl}, 20 \% \mathrm{w} / \mathrm{v}$ PEG 3350 and $0.1 \mathrm{M}$ sodium cacodylate $\mathrm{pH} 6$. Diffraction data for the LT-IIb/NeuAc-nLT complex was collected to $1.72 \AA$ on ID23-2 beamline using a Pilatus detector at the ESRF, Grenoble. Diffraction images were integrated using XDS program [24], and all further processing done using the CCP4 program suite [25].

\section{Structure determination and refinement}

The structure was solved by molecular replacement with PHASER [26] using the coordinates from the B-pentamer of the LT-IIb structure (PDB ID 1TII) as search model. The initial model was optimized using ARP/wARP [27] prior restrained maximum likelihood refinement with REFMAC 5.8 [28] iterated with manual rebuilding in Coot [29]. Five percent of the observations were set aside for cross-validation analysis, and hydrogen atoms were added in their riding positions and used for geometry and structure-factor calculations. Incorporation of the ligand was performed after inspection of the $2 \mathrm{~F}_{\mathrm{o}}-\mathrm{F}_{\mathrm{c}}$ weighted maps. Water molecules, introduced automatically using Coot, were inspected manually. The quality of the models was assessed using the PDB validation server (http://wwpdb-validation.wwpdb.org/validservice/) and coordinates were deposited in the Protein Data Bank under code 5G3L.

\section{RESULTS}

\section{Recombinant expression and purification of LT-IIb B-subunits}

The LT-IIb B-subunit was isolated in high yield, i.e. $30 \mathrm{mg}$ of protein was obtained from $2 \mathrm{~L}$ culture medium. The purified protein migrated as a single band, and the apparent molecular weight of the monomeric protein was in agreement with the predicted molecular mass of 
$\sim 11.8 \mathrm{kDa}$ (Figure S1 in Suppl. Mat., lanes 3-5). The pentameric form of the LT-IIb Bsubunit appears to run at a molecular weight of approximately $50 \mathrm{kDa}$ in agreement with the predicted molecular mass (Figure S1 in Suppl. Mat., lanes 7-9). The protein was stable in several of the solvents tested, allowing us to store it in the refrigerator at $4{ }^{\circ} \mathrm{C}$ for weeks, without seeing a change in its activity. The protein thermostability and its buffer preference was determined using thermal shift assays, showing the highest $\mathrm{T}_{\mathrm{m}}$, of $77^{\circ} \mathrm{C}$ in HEPES buffer pH 8.5 with $20 \mathrm{mM} \mathrm{NaCl}$ (Figure S2 in Suppl. Mat.).

\section{Binding of LT-IIb B-subunits to mixtures of gangliosides}

First the binding of radiolabeled LT-IIb B-subunits to mixtures of acid and non-acid glycosphingolipid fractions from various sources was tested. Thereby a distinct binding to some slow-migrating compounds in the acid fractions from rabbit thymus (Figure 1B, lane 1) and human neutrophils (Figure 1B, lane 2) was obtained. The binding-active gangliosides migrated at the level of sialyl-neolactotetraosylceramide (Figure 1, lane 7) and sialylneolactohexaosylceramide (Figure 1 lane 8), both of which were also recognized by the Bsubunits. Taken together, this suggested a recognition of gangliosides with neolacto core chains, since this core chain is predominant among the gangliosides of both rabbit thymus and human neutrophils [30-33]. Binding of LT-IIb B-subunits to a minor slow-migrating compound in the acid fractions of human small intestine was also observed (Figure 1B, lanes 3-5).

\section{Binding of LT-IIb B-subunits to reference gangliosides}

Next, the binding of radiolabeled LT-IIb B-subunits to a collection of variant gangliosides

[18] was examined (Figure 2 and Figures S3 and S4 in Suppl. Mat.). The results of the binding assays are summarized in Table 1). As reported previously [8,9] the B-subunits 
bound to the GDla ganglioside, while no binding to the GD1b or GT1b gangliosides was obtained.

In addition, the B-subunits of LT-IIb bound to a number of gangliosides with neolacto core, as NeuAc $\alpha 3$ - and NeuGc $\alpha 3$-neolactotetraosylceramide, NeuAc $\alpha 3-$ and NeuGc $\alpha 3-$ neolactohexaosylceramide, NeuAc $\alpha 3$ - and NeuGc $\alpha 3$-neolactooctaosylceramide, the G-10 ganglioside and the G9-B ganglioside. Binding to the VIM-2 ganglioside was also occasionally obtained. However, several gangliosides with neolacto core were not recognized. Thus, a terminal disialyl unit, as in NeuAc $\alpha 8 \mathrm{NeuAc \alpha 3-neolactotetraosylceramide} \mathrm{was} \mathrm{not}$ tolerated, and the gangliosides with terminal $\alpha 6$-linked sialic acid (NeuAco6neolactotetraosylceramide and NeuAc $\alpha 6$-neolactohexaosylceramide) were not recognized. Furthermore, no binding to gangliosides with a sialyl-Le ${ }^{\mathrm{x}}$ epitope occurred. Other nonbinding compounds were the gangliosides GM1, GM3, GM2, GD3 and NeuAco3globotetraosylceramide (not shown). No binding of LT-IIb to non-acid glycosphingolipids as e.g. neolactotetraosylceramide or gangliotetraosylceramide occurred, demonstrating that the terminal $\alpha 3$-linked sialic acid of NeuAc $\alpha 3-/ \mathrm{NeuGc} \alpha 3$-neolactotetraosylceramide and the GD1 a ganglioside, is necessary for for LT-IIb carbohydrate binding.

\section{Binding of LT-IIb B-subunits to dilutions of gangliosides}

Dilutions of gangliosides on thin-layer chromatograms were used for estimation of the relative binding affinities of LT-IIb for the binding active gangliosides. Here. NeuGco3-

neolactohexaosylceramide was the preferred ligand with a detection limit at less than $20 \mathrm{ng}$ (Figure S5B, lane 10), while the detection limits for NeuAc $\alpha 3$-neolactotetraosylceramide and the GD1a ganglioside were approximately $800 \mathrm{ng}$ (Figure S5A, lane 3). 


\section{Human small intestinal ganglioside recognized by LT-IIb B-subunits}

The slow-migrating LT-IIb B-subunit binding ganglioside of human small intestine was isolated by repeated chromatographies on silicic acid and Iatrobeads columns, and the preparative procedure was monitored by binding of radiolabeled LT-IIb B-subunits on thinlayer chromatograms. Finally, two LT-IIb binding fractions were obtained and designated fractions A-1 and A-2 (Figure 3B, lanes 1 and 2), while the following non-binding fractions were designated A-3 and A-4 (Figure 3B, lanes 3 and 4).

\section{LC-ESI/MS of the human small intestinal ganglioside recognized by LT-IIb B-subunits}

The base peak chromatogram obtained by LC-ESI/MS of the LT-IIb binding ganglioside fraction A-2 from human small intestine had two $\left[\mathrm{M}-2 \mathrm{H}^{+}\right]^{2-}$ ions at $\mathrm{m} / \mathrm{z} 721$ and $\mathrm{m} / \mathrm{z} 941$,

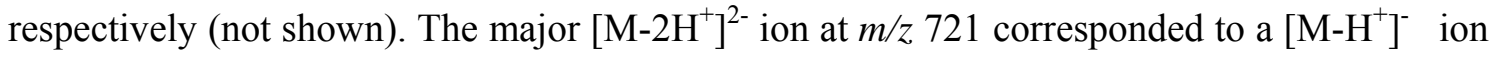
at $m / z$ 1442, indicating a ganglioside with two NeuAc, two Hex, and d18:1-16:0 ceramide, and the mass spectrum obtained by $\mathrm{MS}^{2}$ spectrum of the ion at $\mathrm{m} / \mathrm{z} 721$ was characteristic for the GD3 ganglioside (data not shown).

The $\left[\mathrm{M}-2 \mathrm{H}^{+}\right]^{2-}$ ion at $\mathrm{m} / \mathrm{z} 941$ corresponded to a $\left[\mathrm{M}-\mathrm{H}^{+}\right]^{-}$ion at $\mathrm{m} / \mathrm{z} 1882$, and indicated a ganglioside with one NeuAc, two HexNAc, four Hex, and d18:1-16:0 ceramide. $\mathrm{MS}^{2}$ of the $\left[\mathrm{M}-2 \mathrm{H}^{+}\right]^{2-}$ ion at $\mathrm{m} / \mathrm{z} 941$ (Figure 3C) gave a series of $\mathrm{Y}$ ions $\left(\mathrm{Y}_{0}\right.$ at $\mathrm{m} / \mathrm{z} 536, \mathrm{Y}_{1}$ at $\mathrm{m} / \mathrm{z} 698, \mathrm{Y}_{2}$ at $\mathrm{m} / \mathrm{z}$ 860, $\mathrm{Y}_{3}$ at $\mathrm{m} / \mathrm{z} 1063, \mathrm{Y}_{4}$ at $\mathrm{m} / \mathrm{z} 1225, \mathrm{Y}_{5}$ at $\mathrm{m} / \mathrm{z} 1428$, and $\mathrm{Y}_{6}$ at $\mathrm{m} / \mathrm{z} 1590$ ), which along with the B- and C-type ions, demonstrated a ganglioside with NeuAc-Hex-HexNAc-HexHexNAc-Hex-Hex sequence and d18:1-16:0 ceramide. Thus, LC-ESI/MS allowed identification of NeuAco3-neolactohexaosylceramide in the LT-IIb binding ganglioside fraction isolated from human small intestine. 


\section{Crystal structure of LT-IIb in complex with Sialyl-lacto-N-tetraose}

LT-IIb B-subunit gave crystals between one day to one week with either needle or parallelipipedic morphology, under different conditions (see Supplementary Table S1). In a second step, crystals of LT-IIb B-subunits were optimized manually using 20\% peg 3350, $0.2 \mathrm{M} \mathrm{KCl}$ and $0.1 \mathrm{M}$ buffer $\mathrm{pH}$ 6.0-7.6 and the protein was co-crystallized with NeuAc-nLT Data were collected at $1.72 \AA$ resolution and indexed in the orthorhombic space group $\mathrm{P} 2{ }_{1} 2_{1} 2_{1}$, with unit-cell parameters $\mathrm{a}=48.56, \mathrm{~b}=68.02, \mathrm{c}=154.52 \AA$. The Matthews coefficient [34] indicated the presence of five monomers in the asymmetric unit. The complex structure was solved by molecular replacement with a search for one pentamer using coordinates of PDB 1TII as model [4]. X-ray data collection statistics are shown in Supplementary Table S2. Monomers have been labelled D to $\mathrm{H}$ to follow classical $\mathrm{AB}_{5}$ nomenclature. The monomers forming the B pentamer are almost identical, with root mean square (rmsd) values between 0.24 and $0.14 \AA$ for the 98 equivalent $\mathrm{C} \alpha$. The pentamer is very similar to the one observed for the apo LT-IIb structure used as model with a rmsd of $0.35 \AA$ for the 484 equivalent $\mathrm{C} \alpha$.

Electron density corresponding to carbohydrate ligands was observed in the protein crystal structure. Four of these ligands are positioned in the groove formed between loops of region $12-16$ of one monomer and region $29-36$ of an adjacent one (Figure 4). The Neu5Aca23Gal fragment of the NeuAc-nLT ligand could be modeled in the binding sites of monomers D, G, and H, whereas only the sialic acid moiety could be modelled in monomer E. The rest of the ligand was too disordered to be modelled since it was in the solvent area. No density was observed in the binding site of monomer $\mathrm{F}$ as a result of crystal contacts that would lead to steric conflict with the sialic acid moiety. Additional electron density could also identify a 
sialic acid residue in a non-canonical binding site on the surface or monomer $G$, not far from the occupied binding site in the same monomer (Figure 4).

The groove between $\mathbb{R}$ Rmonomers correspond to the expected binding site since proteins with OB-fold (a five-stranded closed $\beta$ barrel) uses the same face and regions to bind saccharide or nucleotides [35]. Nevertheless, the binding mode is completely different to the one observed for GM1 in LT-I or CT. Since the binding mode is very similar in the four occupied sites only monomer $\mathrm{D}$ is described in continuation. The terminal Neu5Ac residue of NeuAc-nLT establishes most contacts. The pyranose ring of NeuAc is sandwiched between the indole ring of $\operatorname{Trp} 92_{\mathrm{D}}$ and the side chain of Asn $32_{\mathrm{E}}$, being stabilized by hydrophobic contacts (Figure 5A). Another hydrophobic residue, Ile $30_{\mathrm{E}}$, faces the methyl of the $\mathrm{N}$ acetylamine group. The oxygen atom at $\mathrm{C} 4$ and the $\mathrm{N}$-acetyl group form direct and water mediated H-bonds with the Asn31 $\mathrm{E}$ and Asn $32_{\mathrm{E}}$ residues. The carboxylate group of NeuAc receives hydrogen bonds from both the side chain hydroxyl group and the main chain amine of $\operatorname{Thr} 14_{\mathrm{D}}$, whereas the deoxy carbon at position 2 of the ring makes an hydrophobic contact with the methyl group of Thr $13_{\mathrm{D}}$. The galactose residue presents very limited contact with the protein surface, with only one water bridged hydrogen bond from $\mathrm{O} 4$ oxygen to Arg12 in monomers $\mathrm{G}$ and $\mathrm{H}$ and to neighboring Asn32 in monomer D. These contacts differ due do the two different conformations of the ligand (Supplementary Figure S6). The NeuAc-nLT ligand in positions $\mathrm{G}$ and $\mathrm{H}$ adopts similar conformations, with dihedral angles of $\varphi\left(\mathrm{O}-\mathrm{C}_{2}-\right.$ $\left.\mathrm{O}_{2}-\mathrm{C}_{3}{ }^{\prime}\right)=47$ and $64^{\circ}$, and $\psi\left(\mathrm{C}_{2}-\mathrm{O}_{2}-\mathrm{C}_{3}{ }^{\prime}-\mathrm{C}_{4}{ }^{\prime}\right)=112^{\circ}$ and $103^{\circ}$ at the NeuAc $\alpha 2-3 \mathrm{Gal}$ linkage, whereas a different conformation is seen for monomer $\mathrm{D}\left(\varphi=-69^{\circ}\right.$ and $\psi=110^{\circ}[36]$.

The fifth ligand molecule is observed interacting with monomer G of LT-IIb B-subunit in an alternative position. Only the NeuAc residue could be modeled in the electron density. The 
residue is lying flat in a very shallow domain near the canonical site of monomer G (Figure 5). The carboxylate groups establish hydrogen bonds with side chains of $\operatorname{Arg} 51_{\mathrm{G}}$ and $\mathrm{Tyr} 55_{\mathrm{F}}$ of the neighboring monomer helix, while the glycerol side chains interact with backbone nitrogen of Lys53 $\mathrm{D}$ and Asp54 $\mathrm{D}$ and with side chain of Tyr55 $\mathrm{D}$. Water molecules establish several bridged hydrogen bonds, including with the neighboring oligosaccharide in the canonical binding site of monomer G.

Due to the divergent orientation of the anomeric oxygen residues, our attempt to model a single branched disialylated oligosaccharide, like the GD1a oligosaccharide

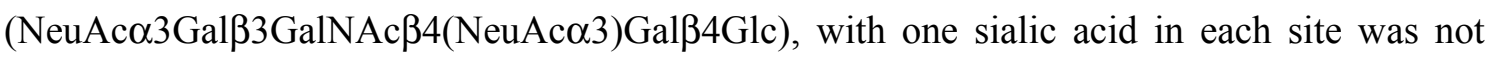
successful. However this hypothesis cannot be completely discarded.

\section{DISCUSSION AND CONCLUSION}

In this study, we have expressed a recombinant LT-IIb B-subunit and investigated the carbohydrate binding specificity by means of solid phase glycosphingolipid binding studies. By binding to a variety of glycosphingolipids separated on thin-layer chromatograms, we found that LT-IIb B-subunits bind with high affinity to gangliosides with neolacto core chain as e.g. NeuGc $\alpha 3$ - and NeuAc $\alpha 3$-neolactohexa- and neolactooctaosylceramide. Previous studies of the carbohydrate recognition by LT-IIb were done using a limited number of gangliosides with ganglio core chain, which explains why the LT-IIb binding to neolacto based gangliosides was overlooked. Furthermore, by isolating LT-IIb binding gangliosides from human small intestine, we established the link between the NeuAc-neolacto gangliosides 
presence on the target tissue and the LT-IIb infection of intestinal cells, where the protein recognition of these antigens promotes the initial steps of the disease.

Lymphocytes are also target cells of LT-IIb, since this protein is a potent adjuvant. Interestingly, the immune responses induced by LT-IIa and LT-IIb are distinctive from those induced by CT or LT-I [37]. While CT and LT-I induce Th2 responses to co-administered antigens, LT-IIa and LT-IIb give a more balanced Th1/Th2 response. These differences have been attributed to the binding of the B-subunits to different ganglioside receptors on lymphocytes [38]. The available data about human lymphocyte gangliosides structures is very limited. However, NeuAc-GM3 is the major ganglioside of both peripheral blood lymphocytes and monocytes, and these cells also have NeuAc-neolactotetraosylceramide [39, 40]. Thus, the identified NeuAc $\alpha 3$-neolacto binding of LT-IIb may also have a role in the immunomodulatory activities of the protein.

The crystal structure of LT-IIb was solved in complex with the carbohydrate moiety of the newly identified ligand NeuAc-neolactotetraosylceramide. Due to the high flexibility of this linear pentasaccharide, only the terminal Neu5Ac 2 2-3Gal disaccharide was observed in most binding sites. Sialic acid binds in the groove that was predicted to be the binding site, based on the $i$ ) overall fold similarity of OB proteins; ii) surface analysis of the crystal structure of the apo-protein; and iii) absence of ganglioside binding in mutants affecting the loop in region 13 and 14 lining the groove [15]. Indeed Thr13 and Thr14 were found critical of GD1a affinity [41], and we demonstrate here that the hydroxyl side chain of Thr14 gives a strong hydrogen bond to the sialic acid carboxylate group, with the methyl group of Thr13 making also hydrophobic contacts with the $\mathrm{CH}_{2}$ at position 2 of NeuAc ring. 
While the NeuAc binding site in LT-IIb is similarly positioned as those observed in CT and LT-I [3] the orientation of the glycan ligand (and therefore the network of contacts) is entirely different (Figure 6 and Figure S7 in Suppl. Mat.). The NeuAc in LT-IIb is rotated about $120^{\circ}$ compared to the one in $\mathrm{CT}$, accompanied with a sliding of the ring. The conformation of GM1 in CT could not be accommodated in LT-IIb binding site due to the conformation adopted by loop 30-35 (31-36 in CT). This loop conformation makes the binding site tighter in that position when compared with CT, efficiently tucking the NeuAc residue in that particular orientation. There are considerable differences - size and conformation wise - between loops 50-54 of LT-IIb and the corresponding (51-60) in CT. In CT, this loop is considerably bigger forming a second wall of a trench/gate, where the other end of the GM1 interacts.

A secondary binding site with affinity for blood group determinants has been identified on the side of the $\beta$-barrel of CT and LT-I B-subunits $[14,42]$. However, a secondary binding site in the vicinity of the primary site, and accommodating the same ligand, has not previously been found in the B-subunits of V. cholerae or ETEC. In this respect LT-IIb resembles the Shigalike toxins from E. coli where there are three carbohydrate binding sites in each B-subunit, providing an increased binding affinity to the globotriasylceramide receptor [43, 44]. However, at the present time, it is not clear if the secondary binding site could accommodate the second NeuAc of a divalent ligand such as GD1a or if it would bind to different sialylated glycolipids on cell surfaces. Our attempts to fit the two NeuAc residues of a single GD1a oligosaccharides in the two sites were not successful, so the second hypothesis seems to be more likely. 


\section{AUTHOR CONTRIBUTIONS}

Dani Zalem, João P. Ribeiro and Annabelle Varrot carried out the experimental work. All authors contributed to the design of the experimental plans, and analyzed the data. Michael Lebens, João P. Ribeiro, Anne Imberty and Susann Teneberg wrote the manuscript.

\section{ACKNOWLEDGEMENTS}

The authors are grateful to European Synchrotron Radiation Facility, Grenoble, France for access to beamline ID23-2. The use of the LTQ linear quadrupole ion trap mass spectrometer (obtained by a grant from the Swedish Research Council (No. 342-2004-4434) is gratefully acknowledged.

\section{FUNDING INFORMATION}

This study was supported by the Swedish Research Council (Grant No. 12628), the Swedish Cancer Foundation, and governmental grants to the Sahlgrenska University Hospital. The authors also acknowledge the received funding from the European Community's 7th Framework Programme (FP7/2007-2013) under the Marie Curie International Outgoing Fellowship for Career Development (PIOF-GA-2011-298910), BioStruct-X (grant agreement N²83570), the ERASynbio program SynGlycTis (ANR-14-SYNB-0002-02) grants, and to the Labex Arcane for the financial support (ANR-11-LABX-0003-01). 


\section{REFERENCES}

1. Qadri, F., Svennerholm, A.M., Faruque, A.S., and Sack, R.B. (2005) Enterotoxigenic Escherichia coli in developing countries: epidemiology, microbiology, clinical features, treatment, and prevention. Clin. Microbiol. Rev. 18, 465-483

2. Fan, E., Merritt, E.A., Verlinde, C.L., and Hol, W.G. (2000) AB(5) toxins: structures and inhibitor design. Curr. Opin. Struct. Biol. 10, 680-686

3. Beddoe, T., Paton, A.W., Le Nours, J., Rossjohn, J., and Paton, J.C. (2010) Structure, biological functions and applications of the AB5 toxins. Trends Biochem. 35, 411-418

4. van den Akker, F., Sarfaty, S., Twiddy, E.M., Connell, T.D., Holmes, R.K., and Hol, W.G. (1996) Crystal structure of a new heat-labile enterotoxin LT-IIb. Structure 4, 665-678

5. Holmgren, J. (1973) Comparison of the tissue receptors for Vibrio cholerae and Escherichia coli enterotoxins by means of gangliosides and natural cholera toxoid. Infect. Immun. 8, 851-859

6. Orlandi, P.A., Crithley, D.R., and Fishman, P.H. (1994) The heat-labile enterotoxin of Escherichia coli binds to polylactosaminoglycan-containing receptors in CaCo-2 human intestinal epithelial cells. Biochemistry 33, 12886-12895

7. Teneberg, S., Hirst, T.R., Ångström, J., and Karlsson, K.-A. (1994) Comparison of the glycolipidbinding specificities of cholera toxin and porcine Escherichia coli heat-labile enterotoxin: identification of a receptor-active non-ganglioside glycolipid for the heat-labile toxin in infant rabbit small intestine. Glycoconj. J. 11, 533-540

8. Fukuta, S., Magnani, J.L., Twiddy, E.M., Holmes, R.K., and Ginsburg, V. (1988) Comparison of the carbohydrate-binding specificities of cholera toxin and Escherichia coli heat-labile enterotoxins LTh-I, LT-IIa, and LT-IIb. Infect. Immun. 56, 1748-1753 
9. Berenson, C.S., Nawar, H.F., Kruzel, R.L., Mandell, L.M., and Connell, T.D. (2013) Gangliosidebinding specificities of E. coli enterotoxin LT-IIc: Importance of long-chain fatty acyl ceramide. Glycobiology 23, 23-31

10. Nawar, H.F., King-Lyons, N.D., Hu, J.C., Pasek, R.C., and Connell, T.D. (2010) LT-IIc, a new member of the type II heat-labile enterotoxin family encoded by an Escherichia coli strain obtained from a nonmammalian host. Infect. Immun. 78, 4705-4713

11. Sixma, T.K., Pronk, S.E., Kalk, K.H., van Zanten, B.A.M., Berghuis, A.M., and Hol, W.G.J. (1992) Lactose binding to heat-labile enterotoxin revealed by X-ray crystallography. Nature 355, $561-564$

12. Merritt, E.A., Sarfaty, S., van den Akker, F., L'Hoir, C., Martial, J.A., and Hol, W.G.J. (1994) Crystal structure of cholera toxin B-pentamer bound to receptor $\mathrm{G}_{\mathrm{M} 1}$ pentasaccharide. Protein Sci. 3, $166-175$

13. Merritt, E.A., Kuhn, P., Sarfarty, S., Erbe, J.L., Holmes, R.K., and Hol, W.G.J. (1998) The $1.25 \AA$ resolution refinement of the cholera toxin B-pentamer: evidence of peptide backbone strain at the receptor-binding site. J. Mol. Biol. 282, 1043-1059

14. Heggelund, J.E., Burschowsky, D., Björnestad, V.A., Hodnik, V., Anderluh, G. and Krengel, U. (2016) High-resolution crystal structures elucidate the molecular basis of cholera blood group dependence. PLoS Pathog. 12 (4), e1005567.

15. Cody, V., Pace, J., Nawar, H.F., King-Lyons, N., Liang, S., Connell, T.D., and Hajishengallis, G. (2012) Structure-activity correlations of variant forms of the B pentamer of Escherichia coli type II heat-labile enterotoxin LT-IIb with Toll-like receptor 2 binding. Acta Crystallogr. D Biol. Crystallogr. 68, 1604-1612

16. Roche, N., Ångström, J., Hurtig, M., Larsson, T., Borén, T., and Teneberg, S. (2004) Helicobacter pylori and complex gangliosides. Infect. Immun. 72, 1519-1529 
17. Dupeux, F., Rower, M., Seroul, G., Blot, D. and Marquez, J. A. (2011) A thermal stability assay can help to estimate the crystallization likelihood of biological samples. Acta Crystallogr D Biol Crystallogr. 67, 915-919

18. Karlsson, K.-A. (1987) Preparation of total non-acid glycolipids for overlay analysis of receptors for bacteria and viruses and for other studies. Meth. Enzymol. 138, 212-220

19. Samuelsson, B.E., Pimlott, W., and Karlsson, K.-A. (1990) Mass spectrometry of mixtures of intact glycosphingolipids. Meth. Enzymol. 193, 623-646

20. Karlsson, H., Halim, A., and Teneberg, S. (2010) Differentiation of glycosphingolipidderived glycan structural isomers by liquid chromatography-mass spectrometry. Glycobiology 20, 1103-1116

21. Koerner, Jr., T.A.W., Prestegard, J.H., Demou, P.C., and Yu, R.K. (1983) High-resolution proton NMR studies of gangliosides. 1. Use of homonuclear spin-echo J-correlated spectroscopy for determination of residue composition and anomeric configurations. Biochemistry 22, 2676-2687

22. Waldi, D. (1962) Sprühreagentien für die dünnschicht-chromatographie. In: Stahl, E., editor: Dünnschicht-Chromatographie. Berlin: Springer-Verlag: pp. 496-515

23. Svennerholm, L., and Fredman, P. (1980) A procedure for the quantitative isolation of brain gangliosides. Biochim. Biophys. Acta. 617, 97-109

24. Kabsch, W. (2010) XDS. Acta Crystallogr. D Biol. Crystallogr. 66, 125-132

25. Winn, M.D., Ballard, C.C., Cowtan, K.D., Dodson, E.J., Emsley, P., Evans, P.R., Keegan, R.M., Krissinel, E.B., Leslie, A.G.W., McCoy, A., McNicholas, S.J., Mursudov, G.N., Pannu, N.S., Potterton, E.A., Powell, H.R., Read, R.J., Vagin, A., and Wilson, K.S. (2011) Overview of the CCP4 suite and current development. Acta Crystallogr. D Biol. Crystallogr. 67, 235-242 
26. McCoy, J., Grosse-Kunstleve, R.W., Adams, P.D., Winn, M.D., Storoni, L., and Read, R.J. (2007) Phaser crystallographic softvare. J. App. Crystal. 40, 658-674

27. Langer, G., Cohen, S.X., Lamzin, V.S., and Perrakis, A. (2008) Automated macromolecular model building for X-ray crystallography using ARP/wARP version 7. Nat. Prot. 3, 1171-1179

28. Murshudov, G.N., Skubák, P., Lebedev, A.A., Pannu, N.S., Steiner, R.A., Nicholls, R.A., Winn, M.D., Long, F., and Vagin, A.A. (2011) REFMAC5 for the refinement of macromolecular crystal structures. Acta Crystallogr. D Biol. Crystallogr. 67, 355-367

29. Emsley, P., Lohkamp, B., Scott, W.G., and Cowtan, K. (2010) Features and development of Coot. Acta Crystallogr. D. D66, 485-501

30. Iwamori, M., and Nagai, Y. (1981) Ganglioside composition of rabbit thymus. Biochim. Biophys. Acta 665, 205-213

31. He, P., Hu, J., and Macher, B.A. (1993) Glycosphingolipids of rabbit, sheep and pig thymus. Arch. Biochem. Biophys. 305, 350-361

32. Stroud, M.R., Handa, K., Salyan, M.E.K., Ito, K., Levery, S.B., Hakomori, S.-i., Reinhold, B.B., and Reinhold, V.N. (1996) Monosialogangliosides of human myelogenous leukemia HL60 cells and normal human leukocytes. 1. Separation of E-selectin binding from nonbinding gangliosides, and absence of sialosyl-Le ${ }^{\mathrm{X}}$ having tetraosyl to octaosyl core. Biochemistry $\mathbf{3 5}, \mathbf{7 5 8 - 7 6 9}$

33. Stroud, M.R., Handa, K., Salyan, M.E.K., Ito, K., Levery, S.B., Hakomori, S.-i., Reinhold, B.B., and Reinhold, V.N. (1996) Monosialogangliosides of human myelogenous leukemia HL60 cells and normal human leukocytes. 2. Characterization of E-selectin binding fractions, and structural requirements for physiological binding to E-selectin. Biochemistry 35, $770-778$

34. Matthews, B.W. (1968) Solvent content of protein crystals, J Mol Biol, 33, 491 
35. Murzin, A.G. (1993) OB(oligonucleotide/oligosaccharide binding)-fold: common structural and functional solution for non-homologous sequences. EMBO J. 12, 861-867

36 . Imberty, A., and Pérez, S. (2000) Structure, conformation, and dynamics of bioactive oligosaccharides: Theoretical approaches and experimental validations. Chem. Rev. 100, 45674588

37. Hajishengallis, G., and Connell, T.D. (2013) Type II heat-labile enterotoxins: structure, function, and immunomodulatory properties. Vet. Immunol. Immunopathol. 152, 68-77

38. Acre, S., Nawar, H.F., Russell, M.W., and Connell, T.D. (2005) Differential binding of Escherichia coli enterotoxins LT-IIa and LT-IIb and of cholera toxin elicits differences in apoptosis, proliferation, and activation of lymphoid cells. Infect: Immun. 73, 2718-2727

39. Macher, B.A., Klock, J.C., Fukuda, M.N., and Fukuda, M. (1981) Isolation and structural characterization of human lymphocyte and neutrophil gangliosides. J. Biol. Chem. 256, 1968-1974

40. Kiguchi, K., Henning-Chubb, C.B., and Huberman, E. (1990) Glycosphingolipid patterns of peripheral blood lymphocytes, monocytes, and granulocytes are cell specific. J. Biochem. 107, 8-14

41. Connell, T.D., and Holmes, R.K. (1995) Mutational analysis of the ganglioside binding activity of the type II Escherichia coli heat-labile enterotoxin LT-IIb. Mol. Microbiol. 16, $21-31$

42. Holmner, A., Askarieh, G., and Krengel, U. (2007) Blood group antigen recognition by Escherichia coli heat-labile enterotoxin. J. Mol. Biol. 371, 754-764

43. Ling, H., Pannu, N.S., Boodhoo, A., Armstrong, G.D., Clark, C.G., Brunton, J.L. and Read, R.J. (2000) A mutant Shiga-like toxin Iie bound to its receptor Gb3: structure of a group II Shiga-like toxin with altered binding specificity. Structure 8, 253-264 
44. Soltyk, A.M., MacKenzie, C.R., Wolski, V.M., Hirama, T., Kitov, P.I., Bundle, D.R., and Brunton, J.L. (2002) A mutational analysis of the globotriaosylceramide-binding sites of verotoxin VT1. J. Biol. Chem. 277, 5351-5359

45. Barone, A., Säljö, K., Benktander, J., Blomqvist, M., Månsson, J.E., Johansson, B.R., Mölne, J., Aspegren, A., Björquist, P., Breimer, M.E., and Teneberg, S. (2014) Sialyllactotetra: a novel cell surface marker of undifferentiated human pluripotent stem cells. J. Biol. Chem. 289, 18846-18859

\section{FIGURE LEGENDS}

Figure 1. Binding of LT-IIb B-subunits to mixtures of gangliosides. Thin-layer chromatogram after detection with anisaldehyde (A), and autoradiogram obtained by binding of radiolabeled LT-IIb B-subunits (B). The chromatograms were eluted with chloroform/methanol/water 60:35:8 (by volume), and the binding assays were done as described under "Experimental procedures". The lanes were: Lane 1, Acid glycosphingolipids of rabbit thymus, $20 \mu \mathrm{g}$; Lane 2, Acid glycosphingolipids of human neutrophils, $40 \mu \mathrm{g}$; Lane 3, Acid glycosphingolipids of human small intestine (Individual I), $40 \mu \mathrm{g}$; Lane 4, Acid glycosphingolipids of human small intestine (Individual II), $40 \mu \mathrm{g}$; Lane 5, Acid glycosphingolipids of human small intestine (Individual III), $40 \mu \mathrm{g}$; Lane 6, Reference GM3 ganglioside (NeuAc $\alpha 3$ Gal $\beta 4$ Glc $\beta 1 \mathrm{Cer}$ ), $4 \mu \mathrm{g} ;$ Lane $7, \quad$ Reference NeuAc $\alpha 3-$ neolactotetraosylceramide (NeuAc $\alpha 3$ Gal $\beta 4$ GlcNAc $\beta 3$ Gal $\beta 4 G l c \beta 1 C e r), \quad 4 \mu \mathrm{g} ; \quad$ Lane 8 , Reference NeuGc $\alpha 3$-neolactohexaosylceramide (NeuGc $\alpha 3$ Gal $\beta 4$ GlcNAc $\beta 3$ Gal $\beta 4 G l c N A c \beta 3 G a 1 \beta 4 G l c \beta 1 C e r), 2 \mu \mathrm{g}$. 
Figure 2. Binding of LT-IIb B-subunits to reference gangliosides. Thin-layer chromatograms after detection with anisaldehyde (A), and autoradiogram obtained by binding of radiolabeled LT-IIb B-subunits (B). The chromatograms were eluted with chloroform/methanol/water 60:35:8 (by volume), and the binding assays were done as described under "Experimental procedures". The lanes were: Lane 1, NeuGco3neolactohexaosylceramide (NeuGc $\alpha 3$ Gal $\beta 4$ GlcNAc $\beta 3$ Gal $\beta 4 G 1 c N A c \beta 3$ Gal $\beta 4 G l c \beta 1 C$ er $), \quad 1$

$\mu g ; \quad$ Lane $\quad 2, \quad$ G9-B $\quad$ ganglioside

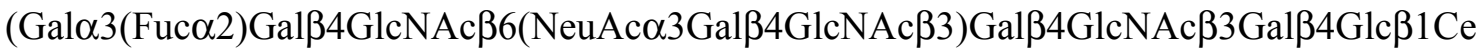

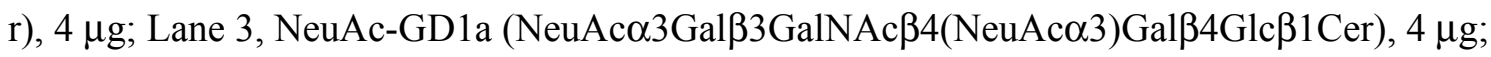

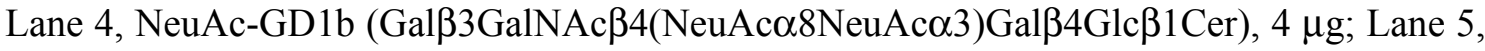

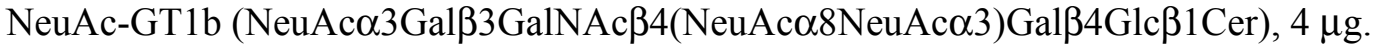

Figure 3. Characterization of LT-IIb binding gangliosides from human small intestine (fraction A-2). (A and B) Binding of LT-IIb B-subunits to human small intestinal gangliosides. Thin-layer chromatogram after detection with anisaldehyde (A), and autoradiogram obtained by binding of radiolabeled LT-IIb B-subunits (B). The chromatograms were eluted with chloroform/methanol/water 60:35:8 (by volume), and the binding assays were done as described under "Experimental procedures". The lanes were: Lane 1, Fraction A-1 from human small intestine, $4 \mu \mathrm{g}$; Lane 2, Fraction A-2 from human small intestine, $4 \mu \mathrm{g}$; Lane 3, Fraction A-3 from human small intestine, $4 \mu \mathrm{g}$; Lane 4, Fraction A-4 from human small intestine, $4 \mu \mathrm{g}$; Lane 5, NeuGco3-neolactohexaosylceramide (NeuGc $\alpha 3$ Gal$\beta 4 G l c N A c \beta 3 G a l \beta 4 G l c N A c \beta 3 G a l \beta 4 G l c \beta 1 C e r), 1 \mu g$; Lane 6 , NeuAc-GD1a

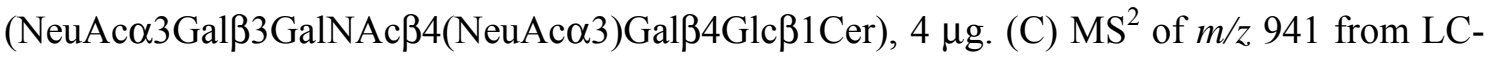
ESI/MS of fraction A-2. (D) Interpretation formula showing the deduced ganglioside sequence. 
Figure 4. LT-IIb B pentamer with NeuAc-nLT bound. Overall representation of the pentamer of subunit B of LT-IIb with the monomers colored by chain. Display of $2 \mathrm{~F}_{\mathrm{o}}-\mathrm{F}_{\mathrm{c}}$ weighted electron density map electron density for the ligands at $1 \sigma\left(0.41 \mathrm{eA}^{3}\right)$

Figure 5. Zoomed in view at the binding of NeuAc-nLT at monomer G. A : Cartoon representation of the primary and "secondary" binding sites of LT-IIb with the bound NeuAcnLT, whose partial structure is shown in stick representation. The LT-IIb residues interacting with the ligand are displayed in green and the formed H-bonds as blue lines. Protein backbone is colored as a function of the monomer. Not all water molecules are shown for simplicity (Note: All highlighted residues belong to monomer $\mathrm{G}$ except for Tyr55 ). B: Surface representation of the surface highlighting the deep NeuAc primary binding site, and the shallow secondary one. Surfaces are colored according to protein monomer.

Figure 6. Comparison of fold and glycan binding site in CT and LT pentamers of Bsubunit. Green : LT-IIb complexed with terminal NeuAco3-neolactohexaosylceramide (this work), yellow LT-I and and pink GM1 complexed with GM1 pentasaccharide (code 2XRQ and $3 \mathrm{CHB}$ respectively). All binding sites are displayed with same orientation of the protein beneath. 
Fig. 1

A. Anisaldehyde detection

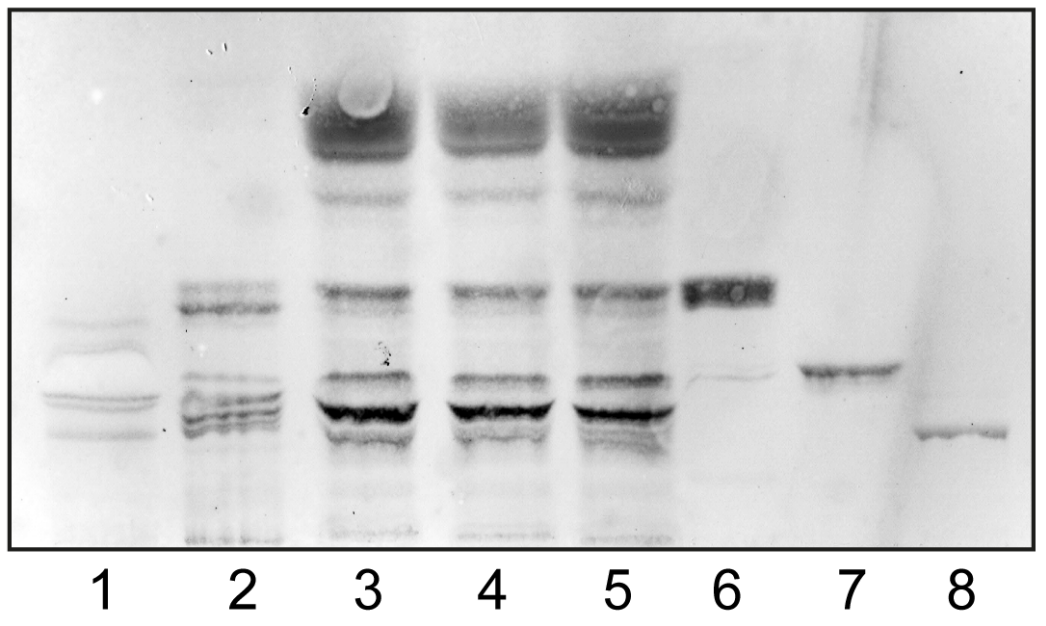

B. LT-IIb B-subunits

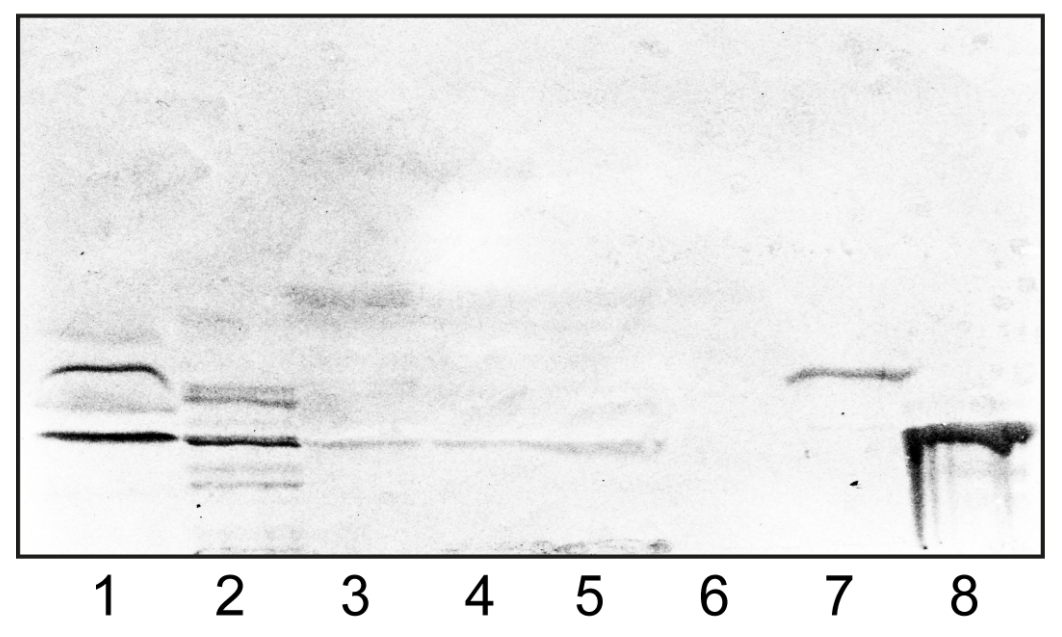


Fig. 2 A. Anisaldehyde detection

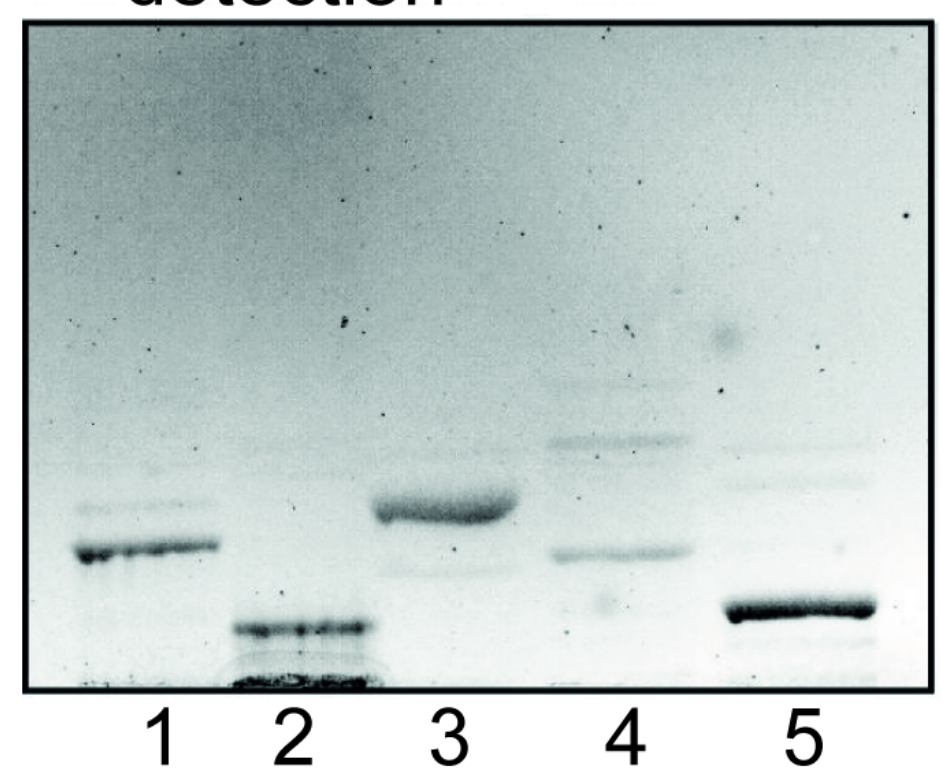

B. LT-IIb B-subunits

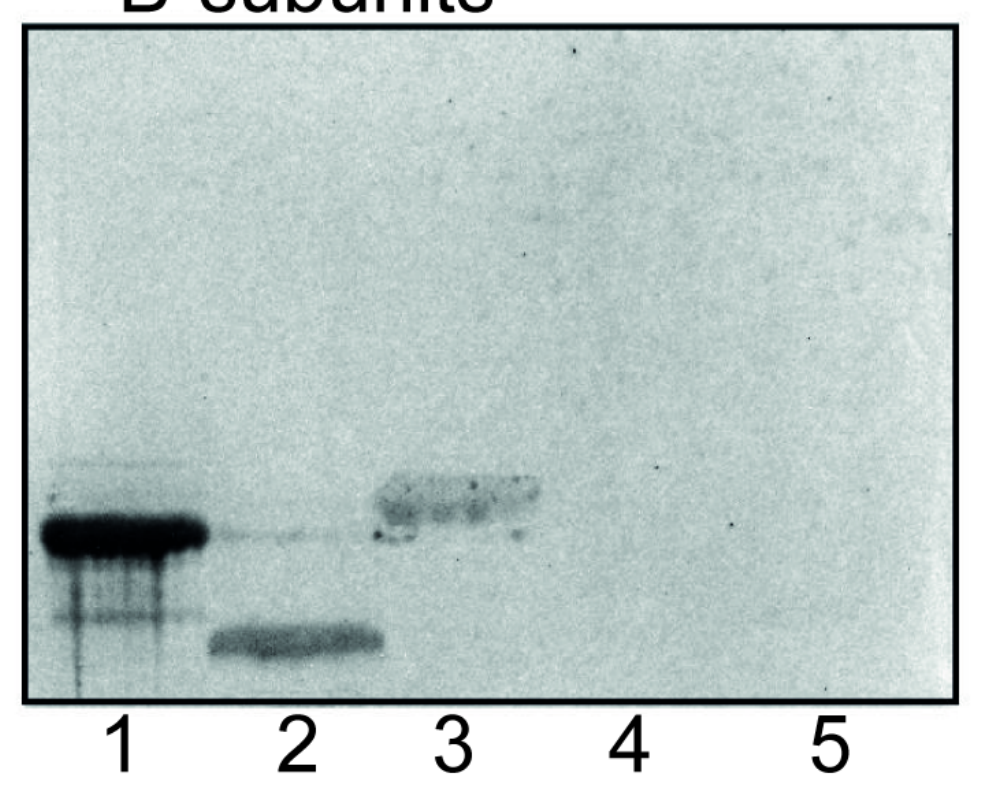


Fig. 3 A. Anisaldehyde detection

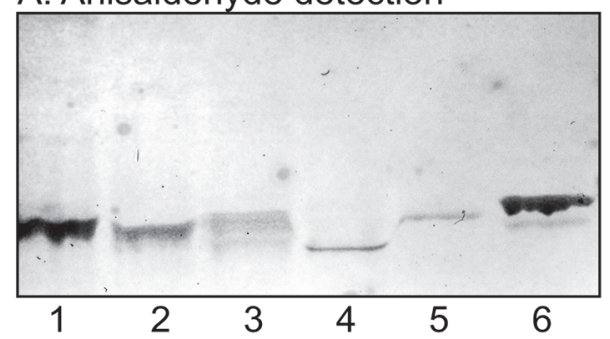

B. LT-Ilb B-subunits

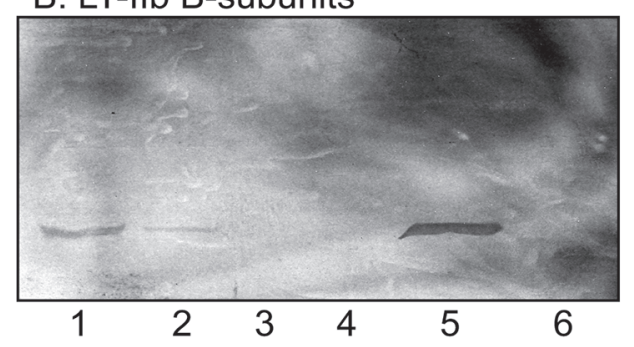

C.

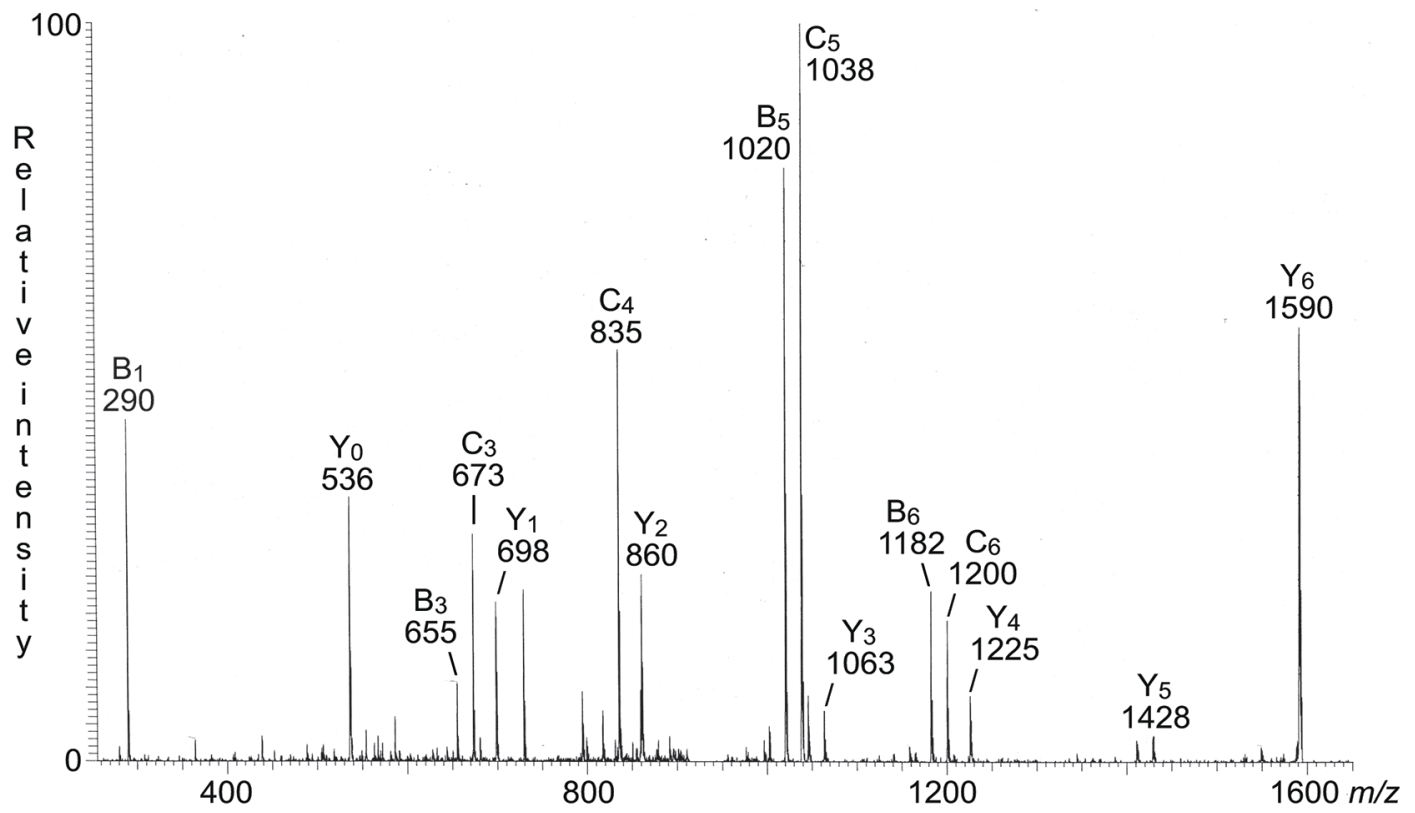

D.

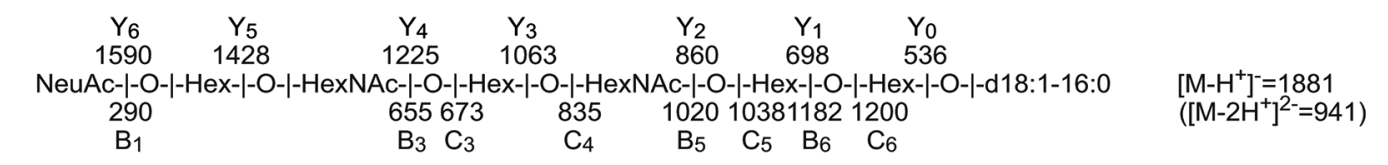


Fig. 4

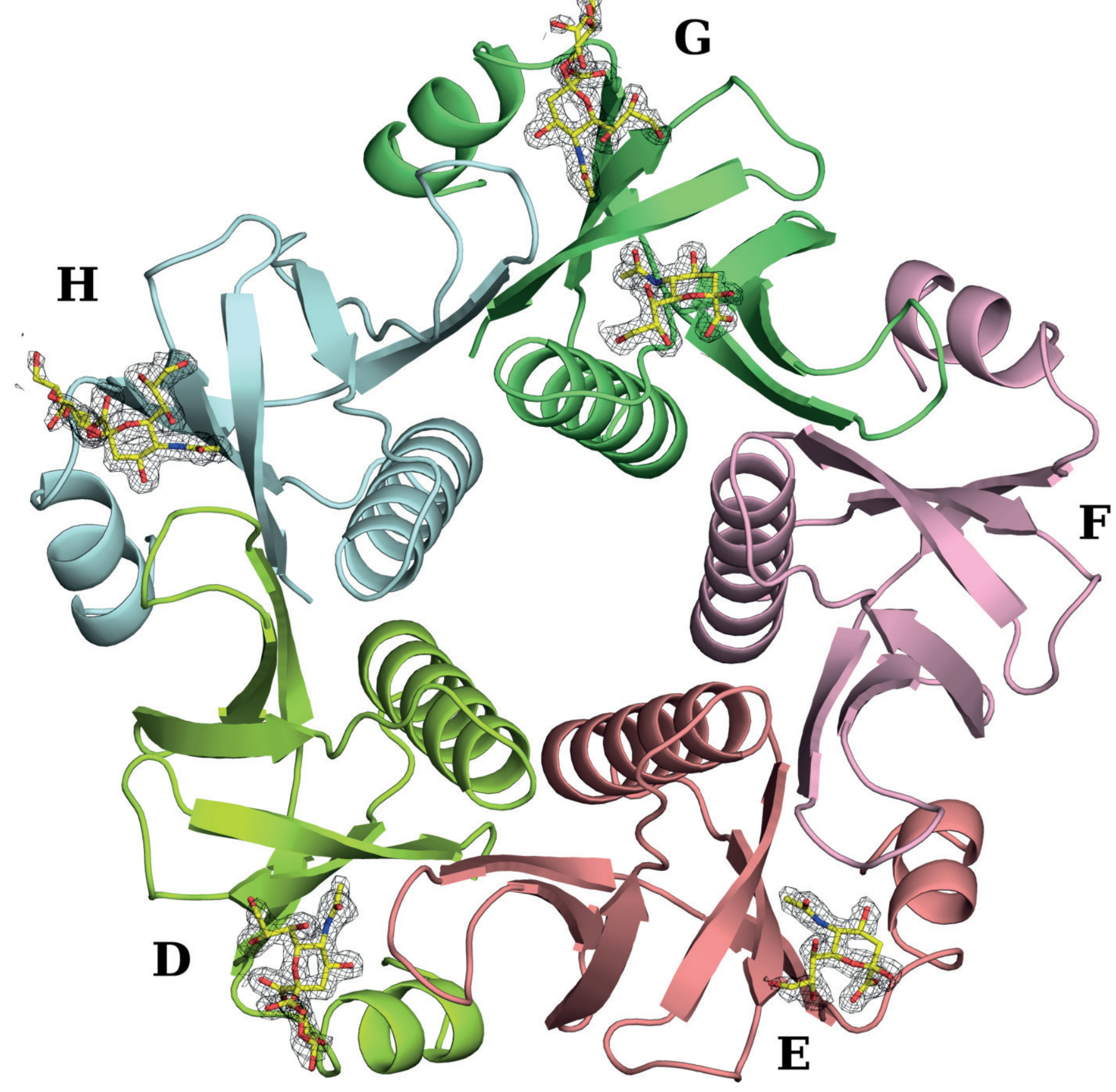


Fig. 5

A

Arg 12

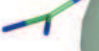

)
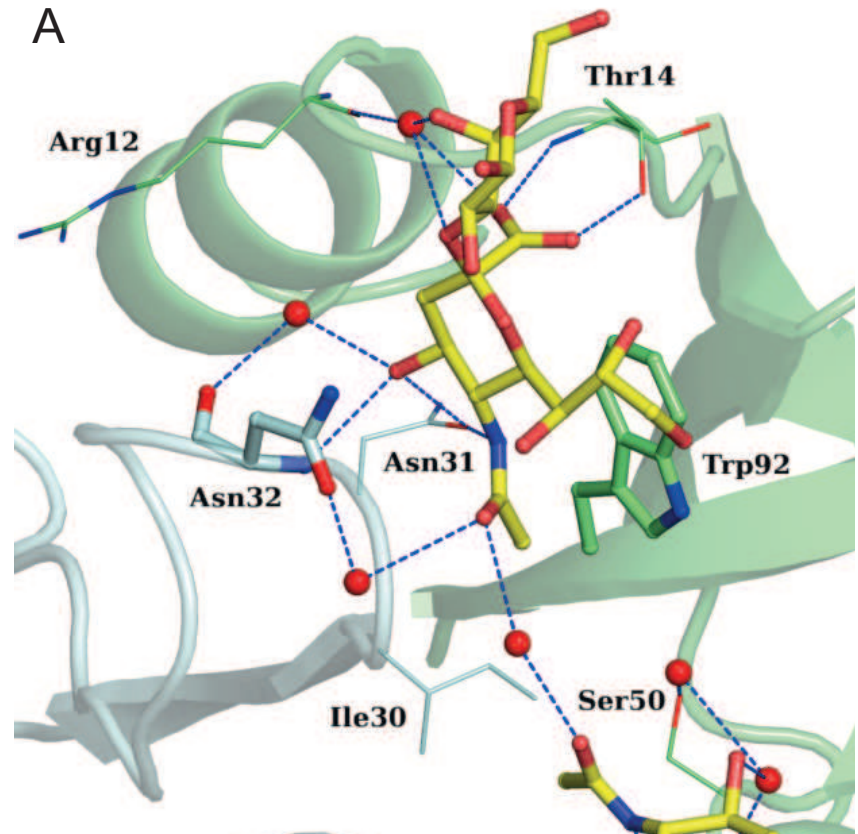

7

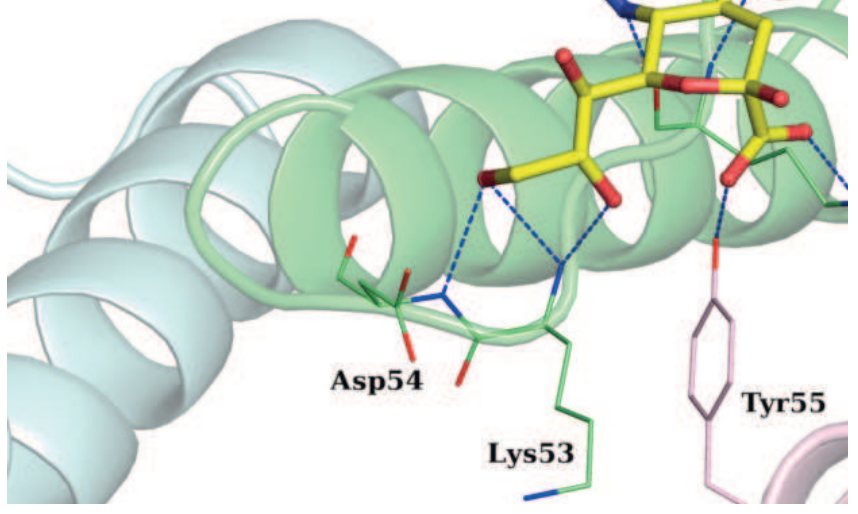

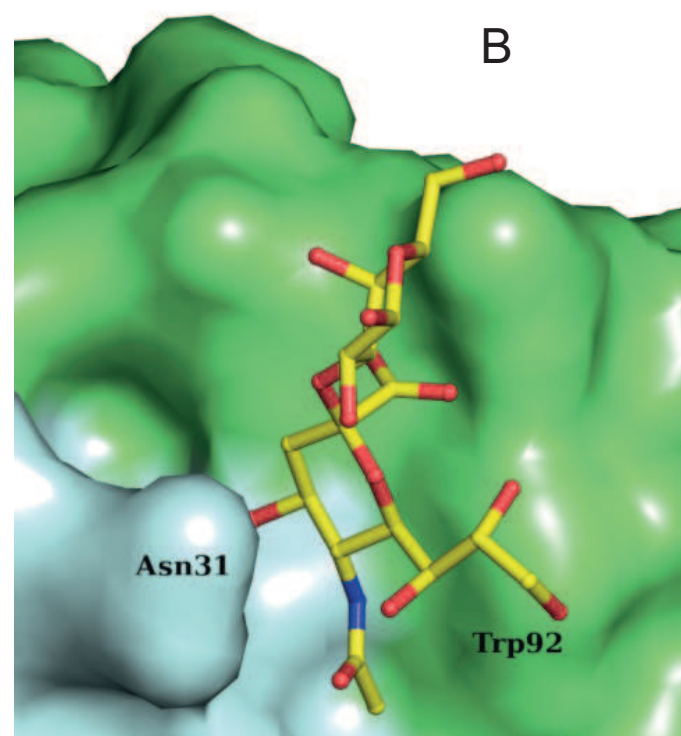

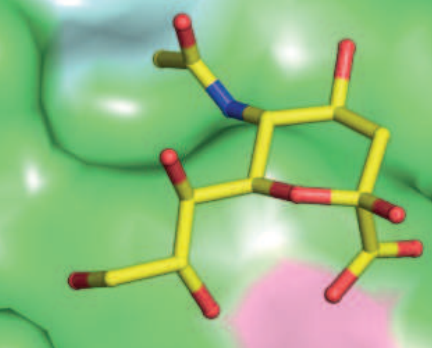

Tyr55 
Fig. 6
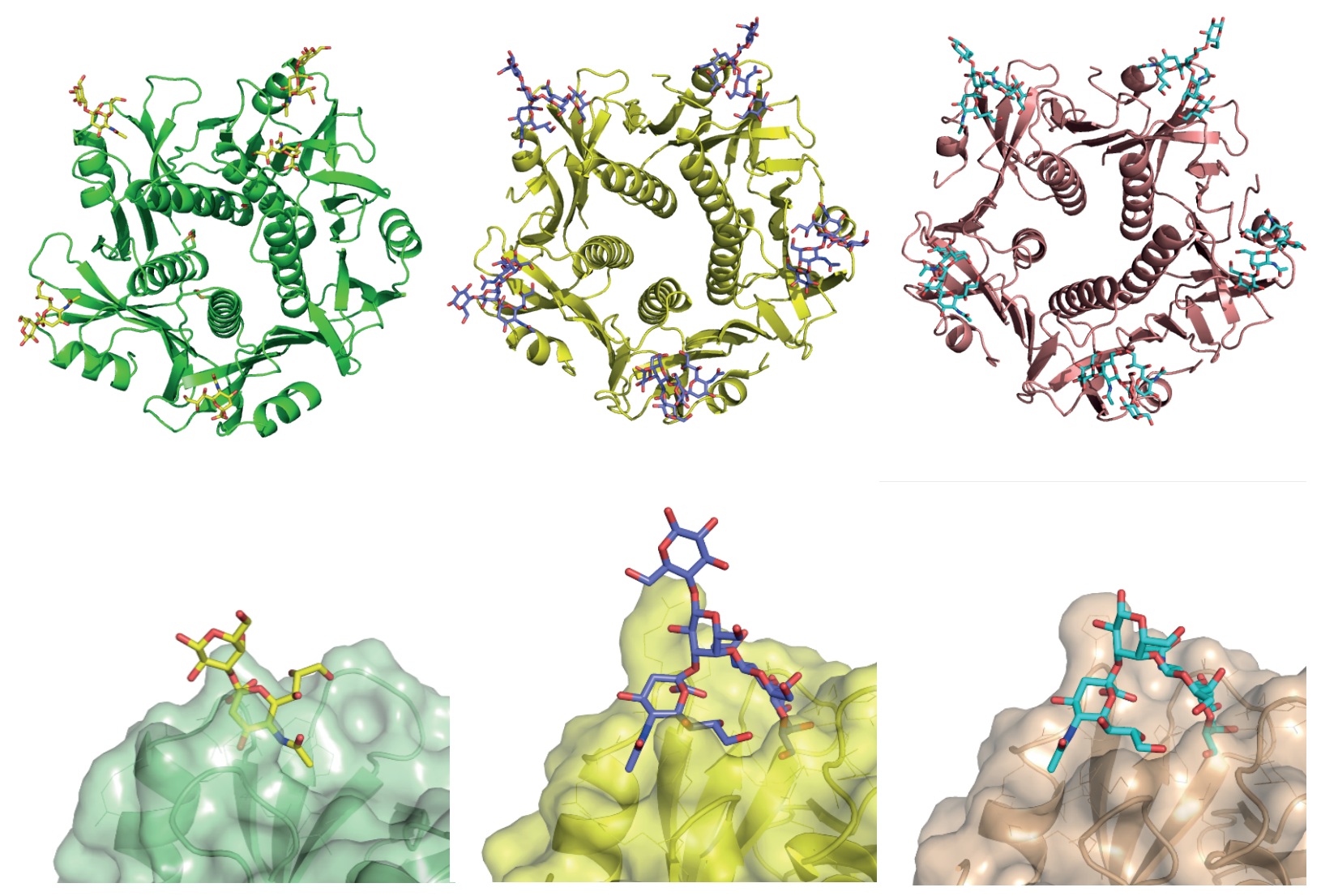
Table 1. Glycosphingolipid binding of LT-IIb B-subunits

\begin{tabular}{|c|c|c|c|}
\hline No. Trivial name & Structure & Binding & Source \\
\hline \multicolumn{4}{|l|}{ Simple compounds } \\
\hline 1. NeuAc-GM3 & NeuAc $\alpha 3 G a l \beta 4 G l c \beta 1 C e r$ & $-\mathrm{a}$ & Human intestine \\
\hline 2. NeuAc-GD3 & NeuAc $\alpha 8$ NeuAc $\alpha 3$ Gal $\beta 4 G$ Glc $\beta 1$ Cer & - & Bovine buttermilk \\
\hline 3. LacCer & Gal $\beta 4$ Glc $\beta 1$ Cer & - & Dog intestine \\
\hline \multicolumn{4}{|l|}{ Lacto/neolacto series } \\
\hline 4. $\mathrm{nLc}_{4}$ & Gal $\beta 4$ GlcNAc $\beta 3$ Gal $\beta 4 \mathrm{Glc} \beta 1 \mathrm{Cer}$ & - & Human neutrophils \\
\hline 5. $\mathrm{nLc}_{6}$ & Gal $\beta 4$ GlcNAc $\beta 6(G a l \beta 4 G l c N A c \beta 3)$ Gal $\beta 4 G l c \beta 1$ Cer & - & Bovine buttermilk \\
\hline 6. H type 2 penta & Fuc $\alpha 2$ Gal $\beta 4$ GlcNAc $\beta 3$ Gal $\beta 4$ Glc $\beta 1$ Cer & - & Human erythrocytes \\
\hline 7. Le ${ }^{\mathrm{a}}$ penta & Gal $\beta 3$ (Fuc $\alpha 4$ )GlcNAc $\beta 3$ Gal $\beta 4$ Glc $\beta 1$ Cer & - & Human intestine \\
\hline 8. B type 2 hexa & Gal $\alpha 3($ Fuc $\alpha 2)$ Gal $\beta 4$ GlcNAc $\beta 3$ Gal $\beta 4$ Glc $\beta 1$ Cer & - & Human erythrocytes \\
\hline 9. A type 1 hexa & GalNAc $\alpha 3$ (Fuc $\alpha 2$ )Gal $\beta 3$ GlcNAc $\beta 3$ Gal $\beta 4 G l c \beta 1$ Cer & - & Human intestine \\
\hline 10. Le ${ }^{b}$ hexa & Fuc $\alpha 2$ Gal $\beta 3$ (Fuc $\alpha 4$ )GlcNAc $\beta 3$ Gal $\beta 4$ Glc $\beta 1$ Cer & - & Human meconium \\
\hline 11. B type 1 hepta & Gal $\alpha 3$ (Fuc $\alpha 2$ )Gal $\beta 3$ (Fuc $\alpha 4$ )GlcNAc $\beta 3$ Gal $\beta 4$ Glc $\beta 1$ Cer & - & Monkey intestine \\
\hline 12. NeuAc $\alpha 3 n c_{4}$ & $\underline{\text { NeuAc } \alpha 3 G a l \beta 4 G l c N A c} \beta 3$ Gal $\beta 4 G l c \beta 1$ Cer $^{b}$ & + & Human erythrocytes \\
\hline 13. NeuGc $\alpha 3 n n_{c}$ & $\underline{\text { NeuGc } \alpha 3 G a l \beta 4 G l c N A c} \beta 3$ Gal $\beta 4 G l c \beta 1$ Cer $^{b}$ & + & Piglet intestine \\
\hline 14. NeuAc $\alpha 6 \mathrm{nLc}_{4}$ & NeuAc $\alpha 6$ Gal $\beta 4$ GlcNAc $\beta 3$ Gal $\beta 4 G l c \beta 1 C e r$ & - & Human meconium \\
\hline 15. $\mathrm{NeuAc}_{2}-\mathrm{nLc}_{4}$ & NeuAc $\alpha 8$ NeuAc $\alpha 3$ Gal $\beta 4$ GlcNAc $\beta 3$ Gal $\beta 4$ Glc $\beta 1$ Cer & - & Human kidney \\
\hline 16. NeuAc $\alpha 3 \mathrm{Lc}_{4}$ & NeuAc $\alpha 3$ Gal $\beta 3$ GlcNAc $\beta 3$ Gal $\beta 4 G l c \beta 1$ Cer & - & Human embryonic stem cells ${ }^{c}$ \\
\hline 17. NeuAc $\alpha 3-$ Le $^{x}$ & $\underline{\text { NeuAc } \alpha 3 \mathrm{Gal} \beta 4}$ (Fuc $\alpha 3$ ) GlcNAc $\beta 3 \mathrm{Gal} \beta 4 \mathrm{Glc} \beta 1 \mathrm{Cer}$ & - & Commercial \\
\hline 18. NeuAc-Sd ${ }^{\mathrm{a}}$ & GalNAc $\beta 4(N e u A c \alpha 3)$ Gal $\beta 4 G l c N A c \beta 3$ Gal $\beta 4 G l c \beta 1$ Cer & - & Moose intestine \\
\hline 19. NeuGc-Sd ${ }^{\mathrm{a}}$ & GalNAc $\beta 4(\underline{N e u G c \alpha 3) \text { Gal } \beta 4 G l c N A c} \beta 3$ Gal $\beta 4$ Glc $\beta 1$ Cer & - & Moose intestine \\
\hline 20. NeuAc $\alpha 3-$ nLc $_{6}$ & NeuAc $\alpha 3 G a l \beta 4$ GlcNAc $\beta 3 G a l \beta 4 G l c N A c \beta 3 G a l \beta 4 G l c \beta 1 C e r$ & +++ & Human hepatoma \\
\hline 21. NeuGco3-nLc 6 & NeuGc $\alpha 3 G a l \beta 4 G l c N A c \beta 3 G a l \beta 4 G l c N A c \beta 3 G a l \beta 4 G l c \beta 1 C e r$ & +++ & Rabbit thymus \\
\hline 22. NeuAc $\alpha 3-n L c_{8}$ & $\underline{\text { NeuAc } \alpha 3 \mathrm{Gal} \beta 4 \mathrm{GlcNAc}} \beta 3 \mathrm{Gal} \beta 4 \mathrm{GlcNAc} \beta 3 \mathrm{Gal} \beta 4 \mathrm{GlcNAc} \beta 3 \mathrm{Gal} \beta 4 \mathrm{Glc} \beta 1 \mathrm{Cer}$ & +++ & Human erythrocytes \\
\hline 23. NeuGco3-nLc 8 & $\underline{\text { NeuGc } \alpha 3 G a l \beta 4 G l c N A c} \beta 3$ Gal $\beta 4 G l c N A c \beta 3 G a l \beta 4 G l c N A c \beta 3 G a l \beta 4 G l c \beta 1 C e r$ & +++ & Rabbit thymus \\
\hline 24. VIM-2 & NeuAc $\alpha 3$ Gal $\beta 4$ GlcNAc $\beta 3$ Gal $\beta 4$ (Fuc $\alpha 3$ )GlcNAc $\beta 3$ Gal $\beta 4$ Glc $\beta 1$ Cer & + & Human colon cancer \\
\hline 25. NeuAc $\alpha 3-\mathrm{Le}^{\mathrm{x}}-\mathrm{nLc} \mathrm{c}_{8}$ & $\underline{\text { NeuAc } \alpha 3 G a l \beta 4}($ Fuc $\alpha 3) \underline{\text { GlcNAc }} \beta 3$ Gal $\beta 4 G l c N A c \beta 3 G a l \beta 4 G l c \beta 1$ Cer & - & Human pancreas cancer \\
\hline
\end{tabular}




\begin{tabular}{|c|c|c|c|}
\hline 26. & Gal $\beta 4$ GlcNAc $\beta 6($ NeuAc $\alpha 6$ Gal $\beta 4$ GlcNAc $\beta 3)$ Gal $\beta 4$ Glc $\beta 1$ Cer & - & Bovine buttermilk \\
\hline 27. & 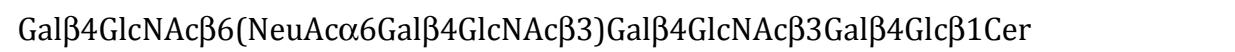 & - & Human meconium \\
\hline 28. NeuAc-G-10 & $\underline{\text { NeuAc } \alpha 3 G a l \beta 4 G l c N A c} \beta 6(\underline{\text { NeuAc } \alpha 3 G a l \beta 4 G l c N A c} \beta 3)$ Gal $\beta 4 G l c N A c \beta 3 G a l \beta 4 G l c \beta 1 C e r$ & + & Human erythrocytes \\
\hline 29. G9-B & Gal $\alpha 3$ (Fuc $\alpha 2)$ Gal $\beta 4$ GlcNAc $\beta 6($ NeuAco3Gal $\beta 4$ GlcNAc $\beta 3)$ Gal $\beta 4$ GlcNAc $\beta 3$ Gal $\beta 4 G l c \beta 1 \mathrm{Cer}$ & + & \\
\hline \multicolumn{4}{|c|}{ Human erythrocytes } \\
\hline \multicolumn{4}{|l|}{ Ganglio series } \\
\hline 30. $\mathrm{GgO}_{3}$ & GalNAc $\beta 4$ Gal $\beta 4$ Glc $\beta 1 \mathrm{Cer}$ & - & Guinea pig erythrocytes \\
\hline 31. $\mathrm{GgO}_{4}$ & Gal $\beta 3$ GalNAc $\beta 4$ Gal $\beta 4 G$ Gc $\beta 1$ Cer & - & Mouse intestine \\
\hline 32. GM2 & GalNAc $\beta 4($ NeuAc $\alpha 3)$ Gal $\beta 4$ Glc $\beta 1$ Cer & - & Human brain \\
\hline 33. GM1 & Gal $\beta 3$ GalNAc $\beta 4($ NeuAc $\alpha 3)$ Gal $\beta 4$ Glc $\beta 1$ Cer & - & Human brain \\
\hline 34. GD1a & $\underline{\text { NeuAc } \alpha 3 G a l \beta 3 G a l N A c} \beta 4($ NeuAc $\alpha 3)$ Gal $\beta 4$ Glc $\beta 1 \mathrm{Cer}$ & +++ & Human brain \\
\hline 35. GD1b & Gal $\beta 3$ GalNAc $\beta 4($ NeuAc $\alpha 8$ NeuAc $\alpha 3)$ Gal $\beta 4$ Glc $\beta 1$ Cer & - & Human brain \\
\hline 36. GT1b & NeuAc $\alpha 3$ Gal $\beta 3$ GalNAc $\beta 4($ NeuAc $\alpha 8$ NeuAc $\alpha 3$ )Gal $\beta 4 G l c \beta 1 \mathrm{Cer}$ & - & Human brain \\
\hline \multicolumn{4}{|l|}{ Globo series } \\
\hline 37. Gb3 & Gal $\alpha 4$ Gal $\beta 4$ Glc $\beta 1$ Cer & - & Human erythrocytes \\
\hline 38. Gb4 & GalNAc $\beta 3$ Gal $\alpha 4$ Gal $\beta 4$ Glc $\beta 1$ Cer & - & Human erythrocytes \\
\hline 39. Forssman & GalNAc $\alpha 3$ GalNAc $\beta 3$ Gal $\alpha 4$ Gal $\beta 4$ Glc $\beta 1$ Cer & - & Dog intestine \\
\hline 40. NeuAc $\alpha 3-G b 4$ & NeuAc $\alpha 3$ GalNAc $\beta 3$ Gal $\alpha 4$ Gal $\beta 4$ Glc $\beta 1$ Cer & - & Human embryonic stem cells \\
\hline
\end{tabular}

a) Binding is defined as follows: +++ denotes an intense and highly reproducible staining when $4 \mu \mathrm{g}$ of the glycosphingolipid was applied on the thin-layer chromatogram, + denotes an occasional staining, while - denotes no binding even at $4 \mu \mathrm{g}$.

b) The NeuAc/NeuGco3Gal $\beta 4 G l c N A c$ and NeuAc $\alpha 3$ Gal $\beta 3 G$ GalNAc sequences are underlined.

c) Binding of LT-IIb to compounds 16 and 40 was evaluated using the slow-migrating ganglioside fraction from human embryonic stem cells (fraction 181C) [45]. 
SUPPLEMENTARY MATERIAL

\section{Biochemical and structural characterization of the novel sialic acid-binding site of Escherichia coli heat-labile enterotoxin LT-IIb}

Table S1. Successful crystallization conditions from assays at High Throughput Crystallization laboratory (HTXlab, Grenoble, France) using LT-IIb B-subunit $\left(10 \mathrm{mg} \mathrm{ml}^{-1}\right)$ in sodium carbonate $50 \mathrm{mM} \mathrm{pH} 9$.

\begin{tabular}{|c|c|c|c|}
\hline Salt & pH, buffer & $\begin{array}{l}\text { Precipitant } \\
(w / v)\end{array}$ & Morphology \\
\hline LiCl $1 \mathrm{M}$ & Trisodium acetate $0.1 \mathrm{M}, \mathrm{pH} 4$ & $20 \%$ PEG 6000 & \multirow{3}{*}{ Needle-like } \\
\hline LiCl $1 \mathrm{M}$ & Citric acid $0.1 \mathrm{M}, \mathrm{pH} 4$ & $30 \%$ PEG 6000 & \\
\hline $\mathrm{LiCl} 1 \mathrm{M}$ & Citric acid $0.1 \mathrm{M}, \mathrm{pH} 5$ & $30 \%$ PEG 6000 & \\
\hline $\mathrm{MgCl}_{2} 0.2 \mathrm{M}$ & $\begin{array}{l}\text { Sodium cacodylate/ } \\
\mathrm{HCl} 0.1 \mathrm{M}, \mathrm{pH} 6.5\end{array}$ & $20 \%$ PEG 1000 & \multirow{9}{*}{ Single crystal } \\
\hline $\mathrm{Na}_{2} \mathrm{HPO}_{4} 0.2 \mathrm{M}$ & - & 20\% PEG 3350 & \\
\hline $\mathrm{Na}_{2} \mathrm{SO}_{4} 0.2 \mathrm{M}$ & Bis-tris propane $0.1 \mathrm{M}$ & $20 \%$ PEG 3350 & \\
\hline $\mathrm{KCl} 0.2 \mathrm{M}$ & - & $20 \%$ PEG 3350 & \\
\hline KI $0.2 \mathrm{M}$ & - & 20\% PEG 3350 & \\
\hline KSCN 0.2M & - & $20 \%$ PEG 3350 & \\
\hline $\mathrm{K} / \mathrm{Na}$ tartare $0.2 \mathrm{M}$ & - & $20 \%$ PEG 3350 & \\
\hline $\begin{array}{l}\text { Trisodium } \\
\text { citrate } 0.2 \mathrm{M}\end{array}$ & - & $20 \%$ PEG 3350 & \\
\hline- & Citric acid $0.1 \mathrm{M}, \mathrm{pH} 4$ & $\left(\mathrm{NH}_{4}\right)_{2} \mathrm{SO}_{4} 1.6 \mathrm{M}$ & \\
\hline
\end{tabular}


Table S2. X-ray data collection and refinement statistics

\begin{tabular}{|c|c|c|c|c|c|}
\hline \multicolumn{6}{|l|}{ Data Collection } \\
\hline Space group & \multicolumn{5}{|c|}{$\mathrm{P} 22_{1} 2_{1}$} \\
\hline $\begin{array}{l}\text { Cell dimensions } \\
\qquad \mathrm{a}, \mathrm{b}, \mathrm{c}(\AA), \alpha, \beta, \gamma(\mathrm{deg})\end{array}$ & \multicolumn{5}{|c|}{$48.56,68.02,154.51,90.0,90.0,90.0$} \\
\hline Nb. reflections & \multicolumn{5}{|c|}{271309} \\
\hline $\mathrm{Nb}$. Unique reflections & \multicolumn{5}{|c|}{54271} \\
\hline resolution $(\AA)$ & \multicolumn{5}{|c|}{$48.56-1.72(1.75-1.72)$} \\
\hline$R_{\text {merge }}$ (within $\mathrm{I}+/ \mathrm{I}-$ ) & \multicolumn{5}{|c|}{$0.07(0.47)$} \\
\hline$I / \sigma(I)$ (within I+/I-) & \multicolumn{5}{|c|}{$2.89(3.00)$} \\
\hline Completeness $(\%)$ & \multicolumn{5}{|c|}{$98.4(96.4)$} \\
\hline redundancy & \multicolumn{5}{|c|}{$5.0(4.5)$} \\
\hline \multicolumn{6}{|l|}{ Refinement } \\
\hline Resolution $(\AA)$ & \multicolumn{5}{|c|}{$46.33-1.72$} \\
\hline $\begin{array}{l}\mathrm{Nb} \text {. Reflections } \\
\mathrm{Nb} \text { free reflections }\end{array}$ & \multicolumn{5}{|c|}{$\begin{array}{l}51509 \\
2713\end{array}$} \\
\hline $\mathrm{R}_{\mathrm{work}}$ & \multicolumn{5}{|l|}{17.1} \\
\hline $\mathrm{R}_{\text {free }}$ & \multicolumn{5}{|l|}{19.6} \\
\hline $\begin{array}{l}\text { rms deviation } \\
\text { bond lengths }(\AA) \\
\text { bond angles (deg) }\end{array}$ & \multicolumn{5}{|l|}{$\begin{array}{l}0.018 \\
1.714\end{array}$} \\
\hline Chain & $\mathrm{D}$ & $\mathrm{E}$ & $\mathrm{F}$ & $\mathrm{G}$ & $\mathrm{H}$ \\
\hline $\mathrm{Nb}$ Atoms protein & 768 & 750 & 749 & 747 & 750 \\
\hline ligand & 32 & 21 & NA & 53 & 32 \\
\hline water & 143 & 117 & 100 & 119 & 110 \\
\hline B factor protein & 17.6 & 17.1 & 16.9 & 16.7 & 15.5 \\
\hline ligand & 31.6 & 34.9 & & 30.6 & 21.0 \\
\hline water & 27.8 & 27.4 & 26.2 & 28.3 & 29.1 \\
\hline $\begin{array}{r}\text { Ramachandran Allowed } \\
\text { Favored } \\
\text { Outliers }\end{array}$ & $\begin{array}{l}99 \\
100 \\
0\end{array}$ & & & & \\
\hline PDB Code & \multicolumn{5}{|l|}{ 5G3L } \\
\hline
\end{tabular}


Figure S1. Purified recombinant LT-IIb B-subunits. LT-IIb B-subunit preparation separated on a $14 \%$ Tris-Glycine gel and stained using Coomassie Brilliant Blue R-250. Lane 1, molecular mass standards; lane 2, boiled CTB; lane 3, boiled LTB-IIb; lane 4, boiled LTBIIb; lane 5, boiled LTB-IIb; lane 6, unboiled CTB; lane 7, unboiled LTB-IIb; lane 8, unboiled LTB-IIb; lane 9, unboiled LTB-IIb. When the pentamer is boiled, it denatures into monomers, with a predicted molecular mass of $\sim 11.8 \mathrm{kDa}$

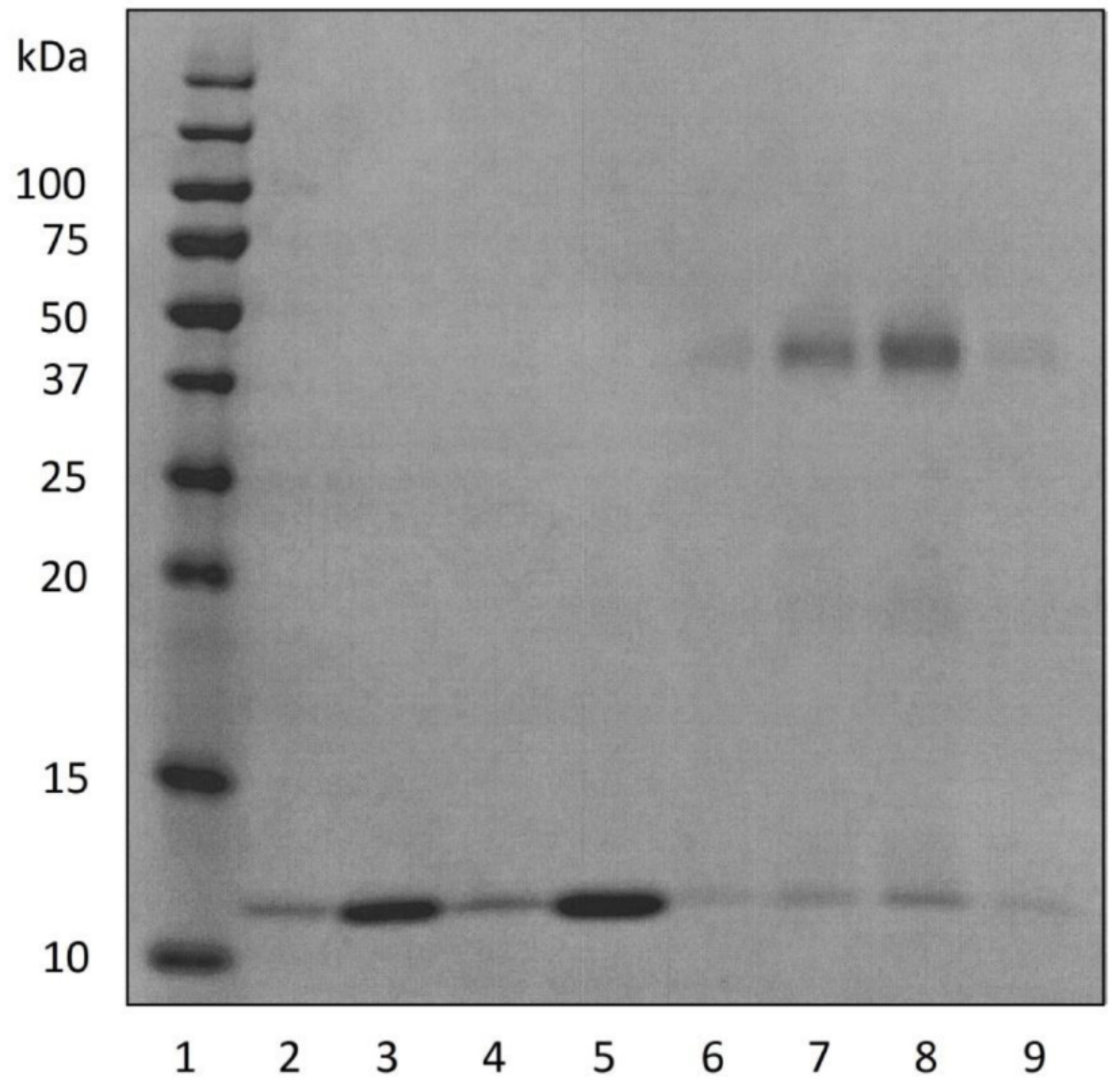


Figure S2. Thermal shift assay (TSA) data for LT-IIb B-subunit (derived curved). Two inflections are seen. The first regards the pentamer dissociation (around $46^{\circ} \mathrm{C}$ ) while the second represents the monomer unfolding, which takes place at higher temperatures. A small $\mathrm{T}_{\mathrm{m}}$ variation $\left(72-77^{\circ} \mathrm{C}\right)$ is seen in these tested conditions. The data for the protein in water pH 7.3 solution is shown in a light blue color; water $+20 \mathrm{mM} \mathrm{NaCl}$, in dark blue; HEPES pH 8.5 , in pink; and HEPES $+20 \mathrm{mM} \mathrm{NaCl}$, in grey.

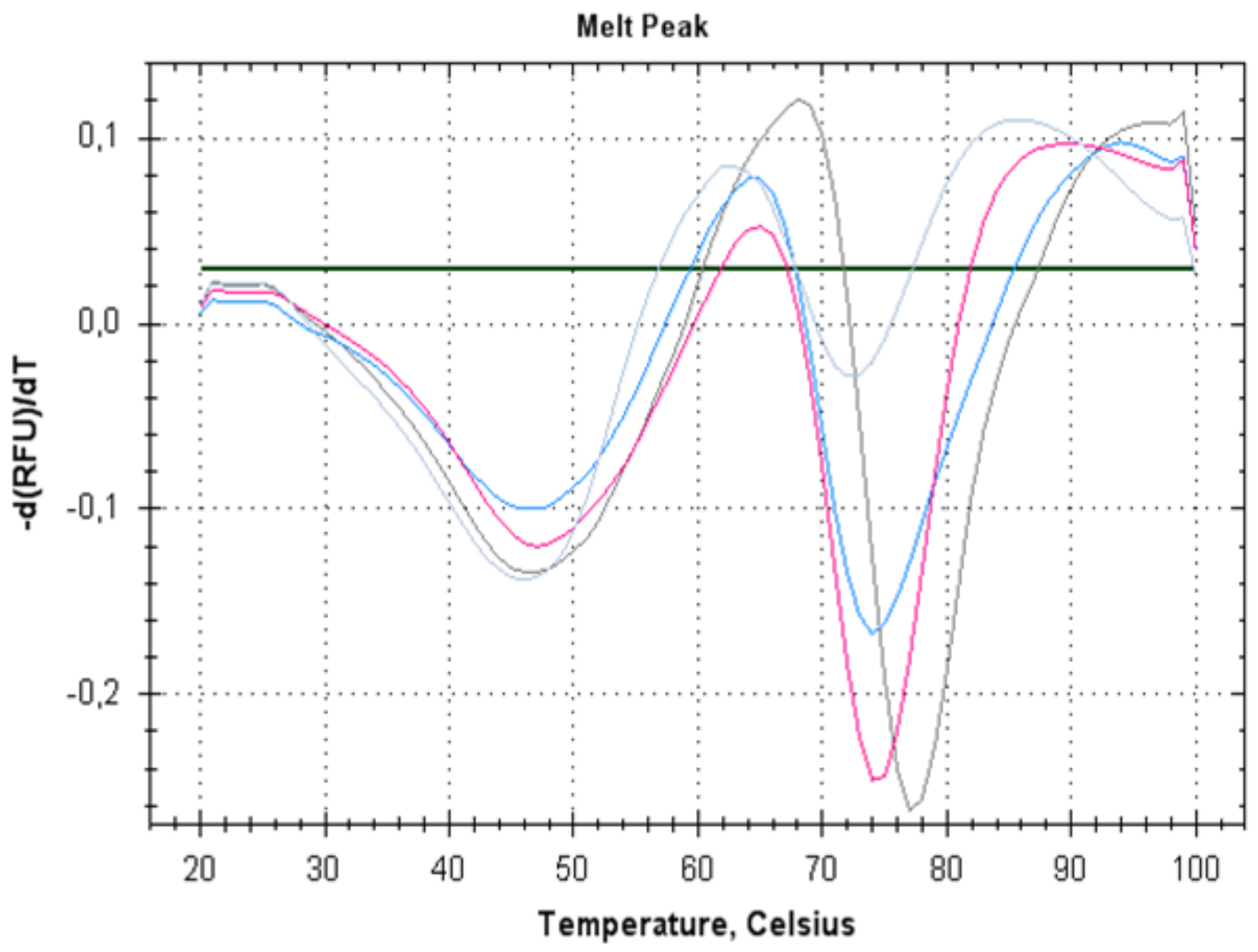


Figure S3. Binding of LT-IIb B-subunits to reference gangliosides . Thin-layer chromatograms after detection with resorcinol (A), and autoradiogram obtained by binding of radiolabeled LT-IIb B-subunits (B). The chromatograms were eluted with chloroform/methanol/water 60:35:8 (by volume), and the binding assays were done as described under "Experimental procedures". The lanes were: Lane 1, NeuAc-GD1a

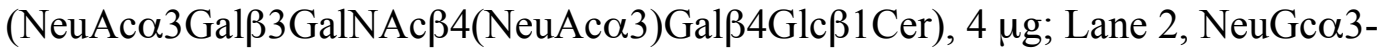
neolactohexaosylceramide (NeuGc $\alpha 3$ Gal $\beta 4$ GlcNAc $\beta 3$ Gal $\beta 4$ GlcNAc $\beta 3$ Gal $\beta 4$ Glc $\beta 1 \mathrm{Cer}$ ), 4 $\mu \mathrm{g}$; Lane 3, NeuAc-G-10 ganglioside (NeuAc $\alpha 3$ Gal $\beta 4$ GlcNAc $\beta 6$ (NeuAc $\alpha 3$ Gal $\beta 4$ GlcNAc $\beta 3$ )Gal $\beta 4$ GlcNAc $\beta 3$ Gal $\beta 4$ Glc $\beta 1$ Cer), 4 $\mu \mathrm{g}$; Lane 4, NeuGca3-neolactohexaosylceramide

(NeuGc $\alpha 3$ Gal $\beta 4$ GlcNAc $\beta 3$ Gal $\beta 4$ GlcNAc $\beta 3$ Gal $\beta 4 G l c \beta 1 C e r)$, and NeuGc $\alpha 3$ neolactooctaosylceramide

(NeuGc $\alpha 3$ Gal $\beta 4$ GlcNAc $\beta 3$ Gal $\beta 4$ GlcNAc $\beta 3$ Gal $\beta 4$ GlcNAc $\beta 3$ Gal $\beta 4$ Glc $\beta 1 C$ Cer), $4 \mu \mathrm{g}$; Lane 5, NeuAc $\alpha 3$-neolactooctaosylceramide

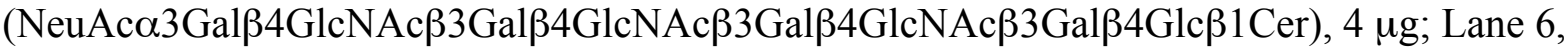
VIM-2 ganglioside (NeuAc $\alpha 3$ Gal $\beta 4$ GlcNAc $\beta 3$ Gal $\beta 4$ (Fuc $\alpha 3$ )GlcNAc $\beta 3$ Gal $\beta 4$ Glc $\beta 1$ Cer), 4 $\mu \mathrm{g}$; Lane 7, NeuAc $\alpha 3-\mathrm{Le}^{\mathrm{x}}$-neolactooctaosylceramide (NeuAc $\alpha 3$ Gal $\beta 4$ (Fuc $\alpha 3$ )GlcNAc $\beta 3$ Gal $\beta 4 G l c N A c \beta 3$ Gal $\beta 4 G l c \beta 1$ Cer), $4 \mu \mathrm{g}$; Lane 8, NeuAca6-neolactohexaosylceramide (Gal $\beta 4$ GlcNAc $\beta 6$ (NeuAc $\alpha 6$ Gal $\beta 4$ GlcNAc $\beta 3)$ Gal $\beta 4$ Glc $\beta 1$ Cer), $4 \mu \mathrm{g}$.

\section{A. Resorcinol detection}

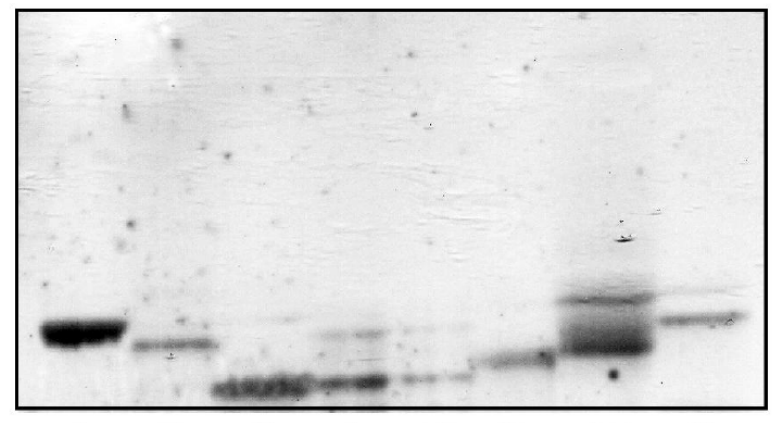

\section{B. LT-IIb B-subunits}

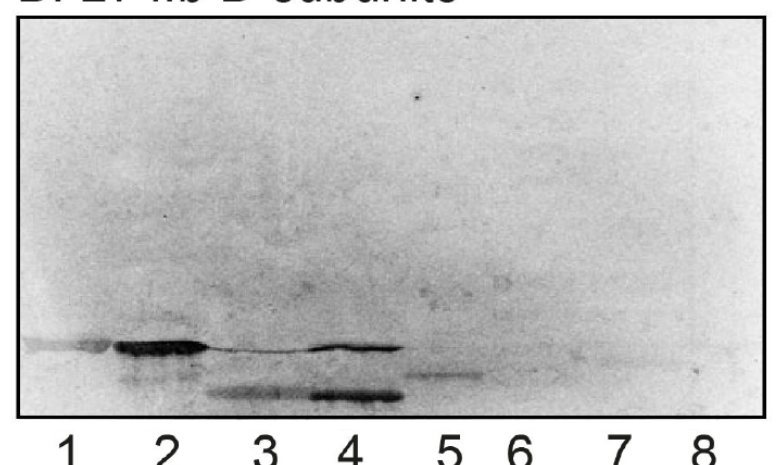


Figure S4. Binding of LT-IIb B-subunits to reference gangliosides. Thin-layer chromatograms after detection with resorcinol (A), and autoradiogram obtained by binding of radiolabeled LT-IIb B-subunits (B). The chromatograms were eluted with chloroform/methanol/water 60:35:8 (by volume), and the binding assays were done as described under "Experimental procedures". The lanes were: Lane 1, NeuAc $\alpha 3-$ neolactotetraosylceramide (NeuAc $\alpha 3$ Gal $\beta 4$ GlcNAc $\beta 3$ Gal $\beta 4$ Glc $\beta 1$ Cer), $4 \mu \mathrm{g}$; Lane 2, NeuGc $\alpha 3$-neolactotetraosylceramide (NeuGc $\alpha 3$ Gal $\beta 4$ GlcNAc $\beta 3$ Gal $\beta 4 G 1 c \beta 1 C e r), 4 \mu \mathrm{g}$; Lane 3, NeuAc $\alpha 6$-neolactotetraosylceramide (NeuAc $\alpha 6$ Gal $\beta 4$ GlcNAc $\beta 3$ Gal $\beta 4$ Glc $\beta 1$ Cer), 4 $\mu \mathrm{g}$; Lane 4, GM1 ganglioside (Gal $\beta 3$ GalNAc $\beta 4(N e u A c \alpha 3)$ Gal $\beta 4 G 1 c \beta 1 \mathrm{Cer}), 4 \mu \mathrm{g}$, and NeuAc $\alpha 8$ NeuAc $\alpha 3$-neolactotetraosylceramide

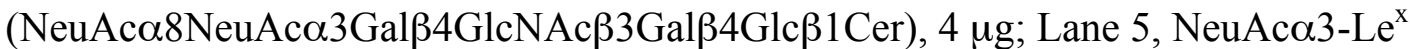

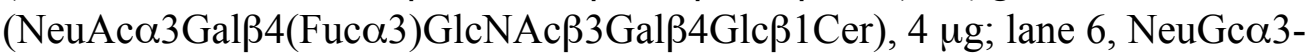
neolactohexaosylceramide (NeuGc $\alpha 3$ Gal $\beta 4$ GlcNAc $\beta 3$ Gal $\beta 4$ GlcNAc $\beta 3$ Gal $\beta 4$ Glc $\beta 1$ Cer), 4 $\mu \mathrm{g}$.

A. Resorcinol detection

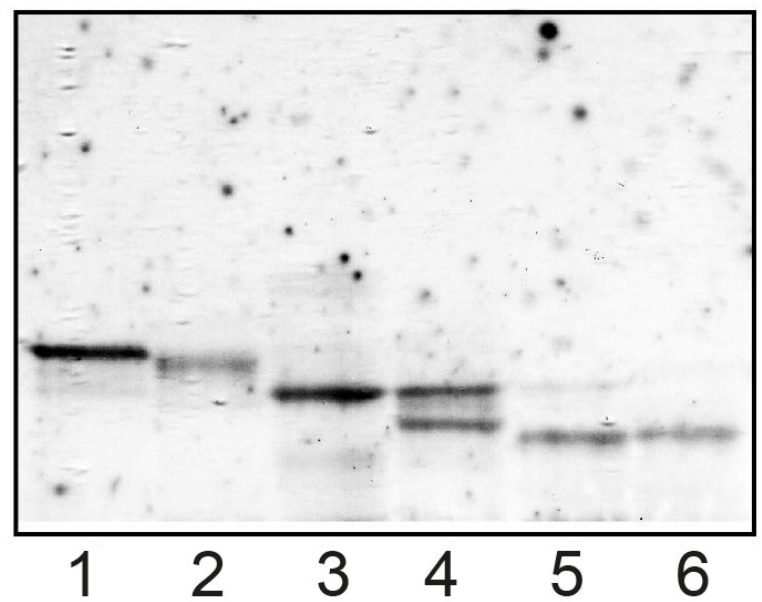

B. LT-Illb B-subunits

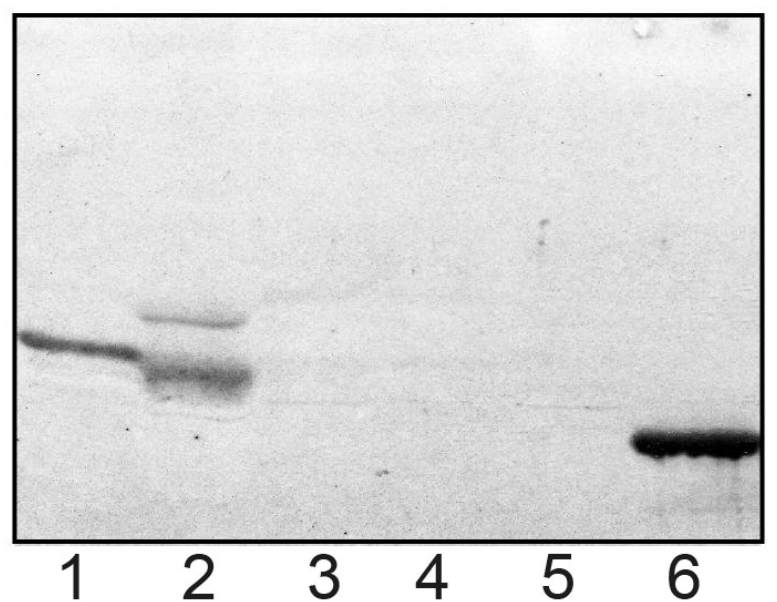


Figure S5. Binding of LT-IIb B-subunits to dilutions of gangliosides. The chromatograms were eluted with chloroform/methanol/water 60:35:8 (by volume), and the binding assay was done as described under "Experimental procedures". The lanes on (A) were: Lane 1, NeuAc $\alpha 3$-neolactotetraosylceramide (NeuAc $\alpha 3-n L c 4$,

NeuAc $\alpha 3$ Gal $\beta 4$ GlcNAc $\beta 3$ Gal $\beta 4$ Glc $\beta 1$ Cer), and GD1a ganglioside

(NeuAc $\alpha 3$ Gal $\beta 3$ GalNAc $\beta 4(N e u A c \alpha 3)$ Gal $\beta 4$ Glc $\beta 1$ Cer), $4 \mu$ g each; Lane 2, NeuAc $\alpha 3-n L c 4$ and GD1a, $2 \mu \mathrm{g}$ each; Lane 3, NeuAc $\alpha 3$-nLc4 and GD1a, 800 ng each; Lane 4, NeuAca3nLc4 and GD1a, 400 ng each; Lane 5, NeuAca3-nLc4 and GD1a, 200 ng each; Lane 6, NeuGc $\alpha 3$-neolactohexaosylceramide (NeuGc $\alpha 3-n L c 6$,

NeuGc $\alpha 3$ Gal $\beta 4$ GlcNAc $\beta 3$ Gal $\beta 4$ GlcNAc $\beta 3$ Gal $\beta 4$ Glc $\beta 1$ Cer), $4 \mu \mathrm{g}$; Lane 7, NeuGc $\alpha 3-n L c 6$,

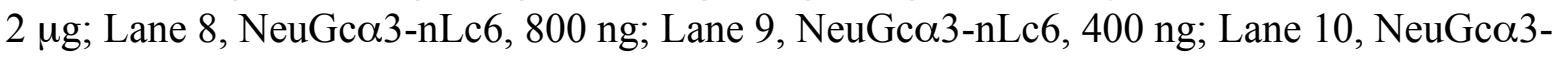
nLc6, $200 \mathrm{ng}$. The lanes on (B) were: Lane 1, NeuAco3-nLc4 and GD1a $800 \mathrm{ng}$ each; Lane 2, NeuAc $\alpha 3-n L c 4$ and GD1a, 400 ng each; Lane 3, NeuAco3-nLc4 and GD1a, 80 ng each; Lane 4, NeuAca3-nLc4 and GD1a, 40 ng each; Lane 5, NeuAca3-nLc4 and GD1a, 20 ng each; Lane 6, NeuGca3-nLc6, 800 ng; Lane 7, NeuGca3-nLc6, 400 ng; Lane 8, NeuGca3nLc6, 80 ng; Lane 9, NeuGca3-nLc6, 40 ng; Lane 10, NeuGca3-nLc6, 20 ng.

\section{A. LT-IIb B-subunits}

NeuAc-nLc4 NeuAc-GD1a

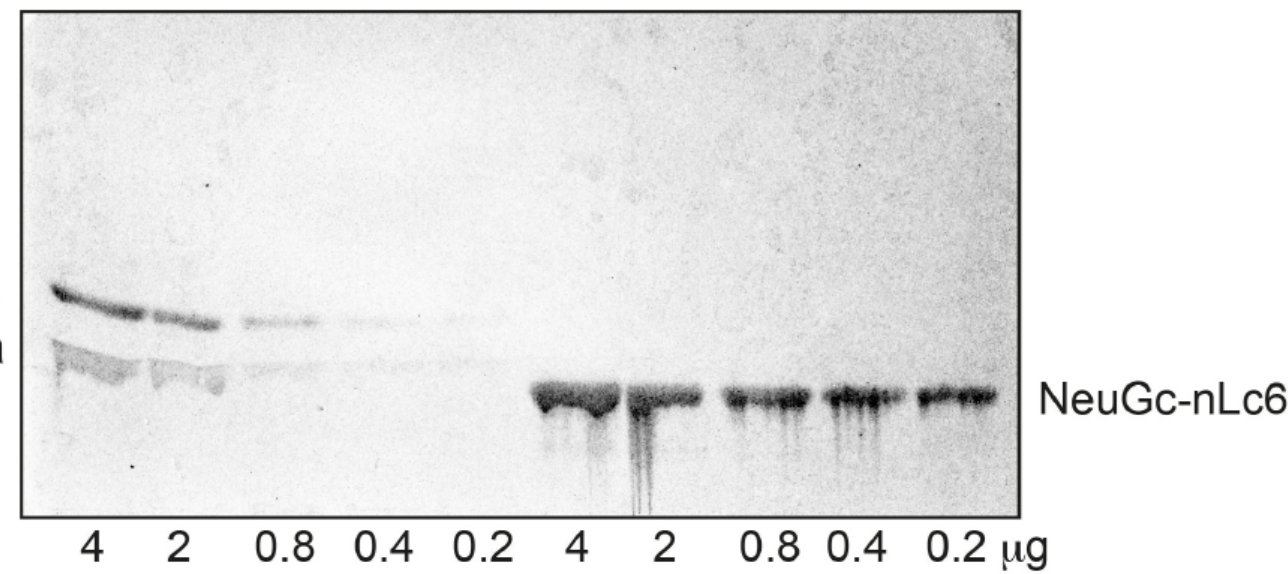

\section{B. LT-IIb B-subunits}

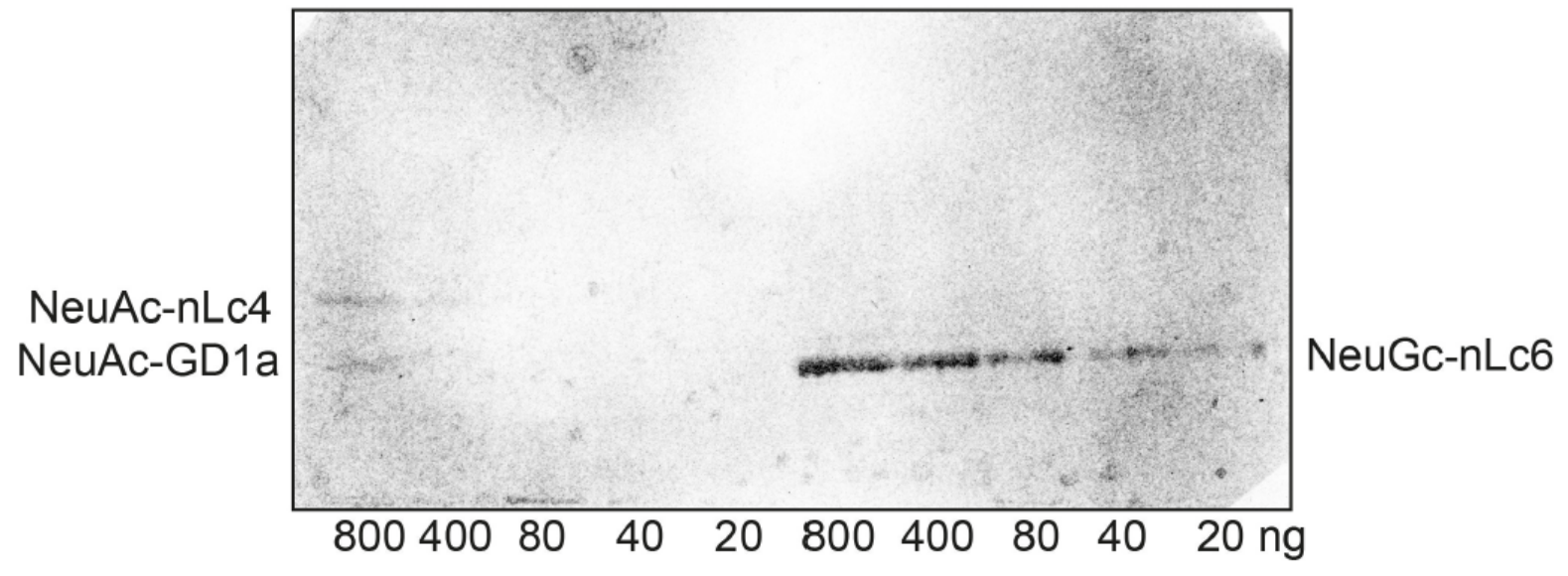


Figure S6. Overlay of the NeuAc-nLT conformations in LT-IIb B-subunit main binding site ( $\mathrm{D}$ and $\mathrm{E}$ monomers are shown with yellow and orange carbons, A monomer is displayed with green carbons). No water molecules are shown for clarity.

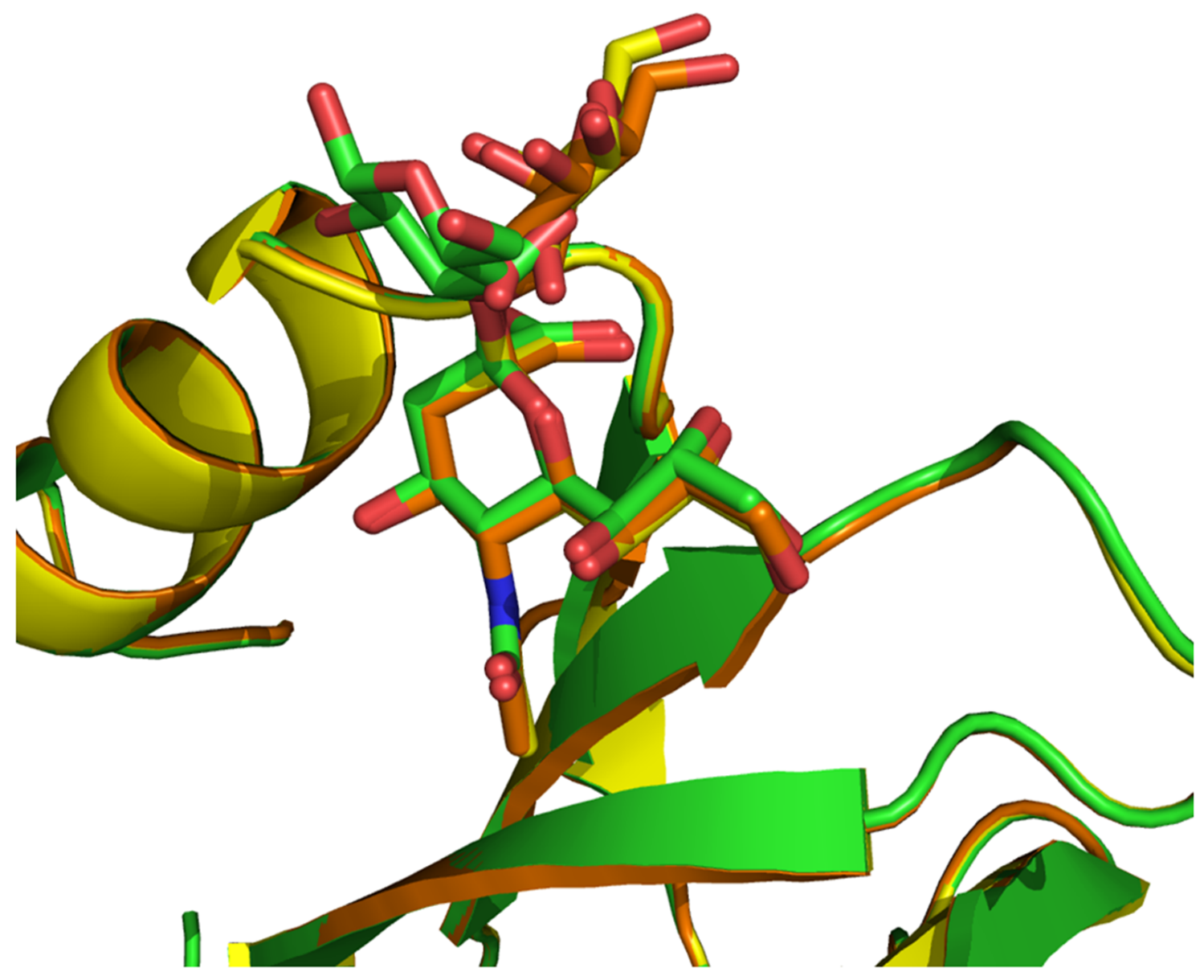


Figure S7. Overlay of binding site of LT-IIb (green) and CT (gray) illustrating the different orientation of NeuAc .

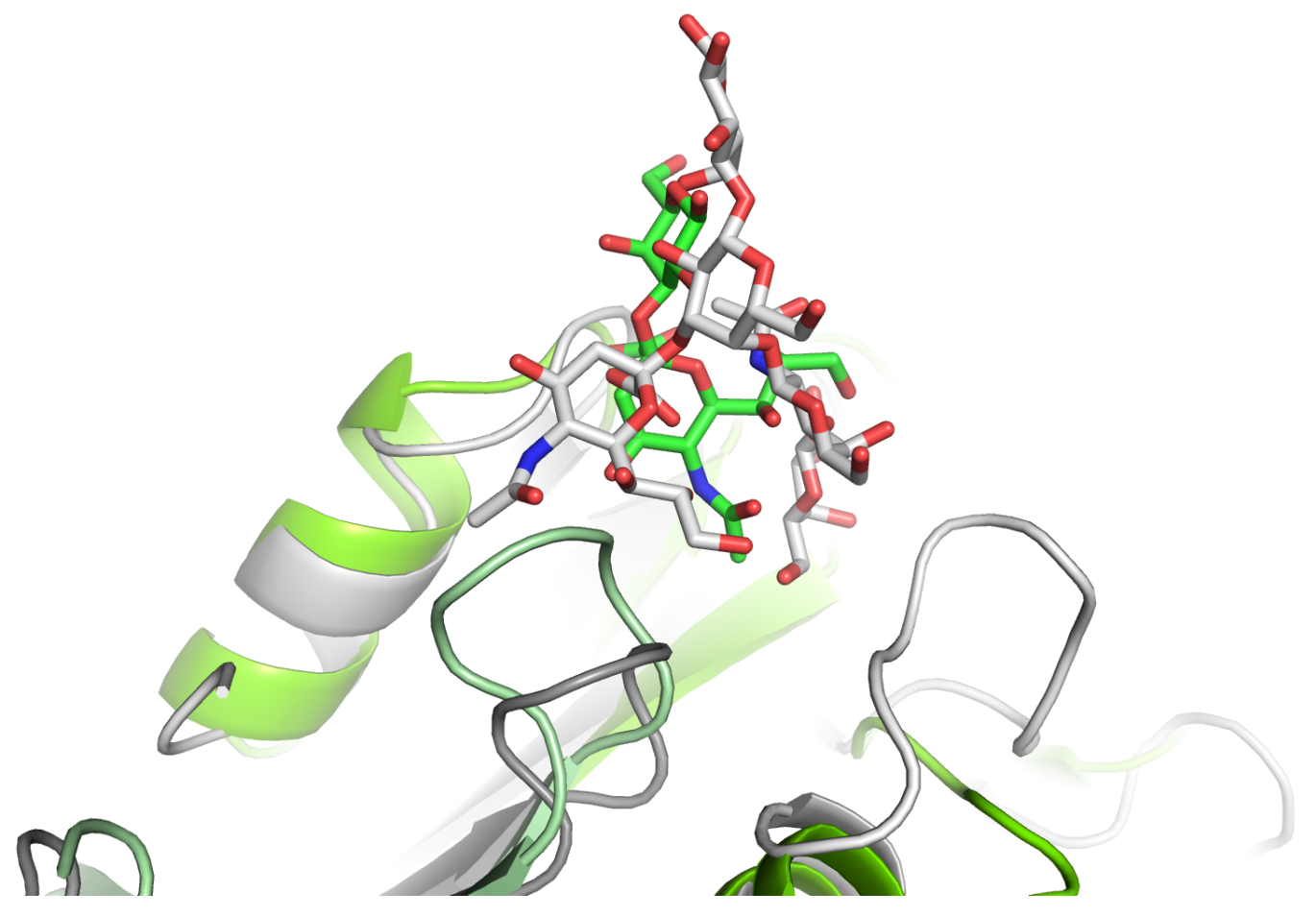

